\title{
Cytochrome-P450-Cytochrome- $b_{5}$ Interaction in a Membrane Environment Changes ${ }^{15} \mathrm{~N}$ Chemical Shift Anisotropy Tensors
}

\author{
Manoj Kumar Pandey ${ }^{1}$, Subramanian Vivekanandan ${ }^{1}$, Shivani Ahuja ${ }^{1}$, Rui Huang ${ }^{1}$, Sang- \\ Choul Im², Lucy Waskell ${ }^{2}$, and Ayyalusamy Ramamoorthy ${ }^{*}, 1$ \\ ${ }^{1}$ Biophysics and Department of Chemistry, University of Michigan, Ann Arbor, Michigan \\ 48109-1055 \\ ${ }^{2}$ Department of Anesthesiology, University of Michigan and VA Medical Center, Ann Arbor, \\ Michigan 48105
}

\begin{abstract}
It has been well realized that the dependence of chemical shift anisotropy (CSA) tensors on the amino acid sequence, secondary structure, dynamics and electrostatic interactions can be utilized in the structural and dynamic studies of proteins by NMR spectroscopy. In addition, CSA tensors could also be utilized to measure the structural interactions between proteins in a protein-protein complex. To this end, here we report the experimentally measured backbone amide- ${ }^{15} \mathrm{~N}$ CSA tensors for a membrane-bound 16.7-kDa full-length rabbit cytochrome- $\mathrm{b}_{5}\left(\mathrm{cytb}_{5}\right)$, in complexation with a 55.8-kDa microsomal rabbit cytochrome P450 2B4 (cytP4502B4). The ${ }^{15} \mathrm{~N}-\mathrm{CSAs}$, determined using the ${ }^{15} \mathrm{~N} \mathrm{CSA} /{ }^{15} \mathrm{~N}-{ }^{1} \mathrm{H}$ dipolar coupling transverse cross-correlated rates, for free cytb $_{5}$ are compared with that for the cytb 5 bound to cytP4502B4. An overall increase in backbone amide- ${ }^{15} \mathrm{~N}$ transverse cross-correlated rates for the cytb ${ }_{5}$ residues in the cytb ${ }_{5}$-cytP450 complex was observed as compared to the free cytb 5 residues. Due to fast spin-spin relaxation $\left(T_{2}\right)$ and subsequent broadening of the signals in the complex, we were able to measure amide- ${ }^{15} \mathrm{~N}$ CSAs only for 48 residues of cytb 5 as compared to 84 residues of free cytb $b_{5}$. We observed a change in ${ }^{15} \mathrm{~N}$ CSA for most residues of cytb $b_{5}$ in the complex, when compared to free cytb $b_{5}$, suggesting a dynamic interaction between the oppositely charged surfaces of anionic cytb 5 and cationic cytP450. The mean values of ${ }^{15} \mathrm{~N}$ CSA determined for residues in helical, sheet and turn regions of cytb ${ }_{5}$ in the complex are $-184.5,-146.8$, and $-146.2 \mathrm{ppm}$, respectively, with an overall average value of $-165.5 \mathrm{ppm}$ (excluding the values from residues in more flexible termini). The measured CSA value for residues in helical conformation is slightly larger as compared to previously reported values. This may be attributed to the paramagnetic effect from $\mathrm{Fe}(\mathrm{III})$ of the heme in cytb $_{5}$, which is similar to our previously reported values for the free cytb ${ }_{5}$.
\end{abstract}

\section{Keywords}

Chemical Shift Anisotropy (CSA) tensor; membrane protein; cytochrome- $\mathrm{b}_{5}\left(\mathrm{cytb}_{5}\right)$; cytochrome P450 (cytP450); CSA/dipolar coupling transverse cross-correlated rates

\footnotetext{
*To whom correspondence should be addressed (ramamoor@umich.edu).

Supporting Information

Tables of amide- ${ }^{15} \mathrm{~N}$ transverse relaxation rates $\left(R_{2}\right)$, transverse cross-correlated rates $\left(\eta_{x y}\right)$, and CSAs for cytb5 obtained from the membrane-bound cytb5-cytP450 complex. A figure showing a comparison of transverse cross-correlated relaxation rates for different secondary structural elements of cytb5 both in the free and bound state with cytP450. This material is available free of charge via the internet at http://pubs.acs.org.
} 


\section{Introduction}

There is a growing interest in determining high-resolution structure and dynamics of biomolecules by NMR spectroscopy. Most biological functions in a cell are controlled by proteins, where a vast majority of proteins interact with one another to form protein-protein complexes that are essential for many biological activities. Protein-protein interactions are mediated through a combination of van der Waals forces, salt bridges, and hydrogen bonding and hydrophobic interactions at a specific binding domain of each protein. The strength of binding is influenced by the size, shape and secondary structure of the binding domains. Recent advances in NMR methodology and instrumentation have provided new approaches for the characterization of these interactions at the atomic-level. The interaction between the local electronic environment and the nucleus, known as a chemical shift anisotropy (CSA) tensor, has been widely used to investigate the structure ${ }^{1-3}$ and dynamics ${ }^{4-6}$ of biomolecules by both solid-state and solution NMR methods. In addition, the structural and dynamic changes due to a protein-protein complex formation could also be studied using well-characterized chemical shift tensors. Computational methods using quantum chemical calculations ${ }^{7-23}$ have also been developed to study the variation of chemical shift tensors. Several solid-state NMR methods have been used to determine CSA tensors ${ }^{24}$ from solids that are site specifically labeled with an isotope (e.g., ${ }^{15} \mathrm{~N}$ or $\left.{ }^{13} \mathrm{C}\right)$ such as static CSA powder patterns, ${ }^{25-27}$ aligned samples, ${ }^{28}$ 2D separated-local-field (SLF) experiments, ${ }^{29,30}$ magic angle spinning (MAS) spectra, ${ }^{31-35}$ recoupling techniques, ${ }^{36,37}$ and the gold standard single-crystal studies. ${ }^{38}$ However, these methods are less applied due to severe spectral overlap for non-selectively (or uniformly) labeled large proteins. On the other hand, this difficulty can be overcome by studying these proteins in solution. Individual components of CSA tensors could not be determined from peak positions in solution as anisotropic interactions are averaged out due to fast tumbling of molecules. Relaxation studies $^{39-49}$ using CSA-dipolar cross-correlated rate measurements ${ }^{50,51}$ are generally implemented to determine CSA values in solution, mostly by measuring the differential line widths of the doublet components obtained in HSQC-IPAP (HSQC: heteronuclear single quantum coherence; IPAP: in-phase anti-phase) ${ }^{52-56} \mathrm{~A}$ recent study reported the internal dynamics of the homotrimeric HIV-1 viral coat protein gp41 in a membrane environment from amide- ${ }^{15} \mathrm{~N}$ relaxation $\left(R_{1}\right.$ and $\left.R_{1 \rho}\right)$ relaxation rates and ${ }^{15} \mathrm{~N}$ NOE in combination with transverse CSA-dipolar coupling cross-correlated relaxation rate measurements. ${ }^{57}$

Theoretical studies based on a model-free method and molecular dynamics simulations have also been used to study the dynamics of ribonuclease HI (RNase H) and Rho-GTPase Binding Domain (RBD) of Plexin-B1 using amide- $-{ }^{15} \mathrm{~N}$ relaxation data ${ }^{58,59}$ Backbone amide $-{ }^{15} \mathrm{~N}$ CSA tensors are very sensitive to backbone torsion angles/secondary structure, amino acid sequence, intra and inter residue hydrogen bonding interaction, intra-residue angle, side chain chemistry, electrostatic interactions and solvent effect. ${ }^{13,60-67}$ Because of this reason, it is a daunting task to accurately and precisely determine amide- $-{ }^{15} \mathrm{~N} \mathrm{CSA}$ as compared to ${ }^{13} \mathrm{C}$ CSA.

In this study, we have determined backbone amide- ${ }^{15} \mathrm{~N}$ CSA tensors for the $16.7-\mathrm{kDa}$ membrane-bound full-length rabbit cytb $b_{5}$ in a $\sim 70-\mathrm{kDa}$ complex, comprised of microsomal rabbit cytP4502B4 (55.8-kDa) and cytb 5 , incorporated in micelles using solution NMR spectroscopy. CytP450 is a heme containing transmembrane protein (anchored to the membrane by the N-terminal hydrophobic helix), ${ }^{68,69}$ which is particularly abundant in both plant and animal tissues and play important roles in enzyme kinetics in a variety of biochemical and physiological processes. ${ }^{70} \mathrm{Cytb}_{5}$, anchored to the membrane by the $\mathrm{C}$ terminal helix, ${ }^{71}$ controls the rate of catalysis of cytP450. ${ }^{72} \mathrm{Cytb}_{5}$ and cytP450 reductase (CPR) act as redox partners of cytP450 to provide electrons for the catalytic reaction where one atom of activated molecular oxygen is inserted to the substrate $\mathrm{S}$, $\left[\mathrm{SH}+\mathrm{O}_{2}+\mathrm{NAD}(\mathrm{P}) \mathrm{H}\right.$ $\left.\rightarrow \mathrm{SOH}+\mathrm{H}_{2} \mathrm{O}+\mathrm{NAD}(\mathrm{P})^{+}\right]$, using two protons from water and two electrons from $\mathrm{NAD}(\mathrm{P}) \mathrm{H}$. 
Although there has been a significant progress towards unraveling NMR structure and dynamics of smaller proteins, our understanding of structure related biological function of larger proteins such as cytP4502B4 and its interaction with other proteins using NMR as a tool still remains a massive task, mainly due to poor sample stability, spectral resolution and sensitivity. We recently reported the first full-length membrane-bound structure of rabbit cytb $_{5}$ (PDB 2M33) determined using a combination of the 2D HIMSELF static solid-state NMR experiments on cytb ${ }_{5}$ incorporated in magnetically-aligned bicelles and solution NMR experiments on cytb $_{5}$ incorporated in isotropic bicelles (or detergent micelles) ${ }^{72}$ (Figure 1A). This study also presented the structure of a highly dynamic electron-transfer complex formed between a full-length membrane-bound cytb $_{5}$ and its redox partner cytP450 using experimentally derived NMR constraints and mutagenesis data (Figure 1B). In the absence of NMR structure for cytP4502B4, we made use of a uniformly-labeled cytb 5 resonances in the IPAP spectra to study its complexation with unlabeled cytP4502B4. Amide- ${ }^{15} \mathrm{~N}$ CSA

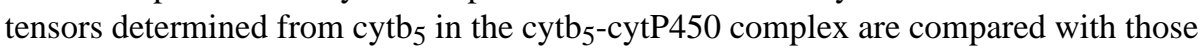
obtained from free cytb 5 .

\section{Experimental Section}

Cytochromes, $\mathrm{b}_{5}$ and $\mathrm{P} 450$, were biologically expressed and purified as explained in our previous publication. ${ }^{722} \mathrm{H}$-dodecylphosphocoline (DPC-D38) and $\mathrm{D}_{2} \mathrm{O}$ were purchased from Cambridge Isotope Laboratories (Andover, MA). Glycerol and buffer components used in NMR experiments were purchased from Sigma-Aldrich and Roche Applied Science. The

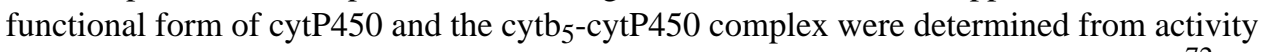

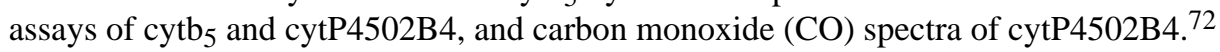

\section{NMR experiments}

A $5 \mathrm{~mm}$ Shigemi tube containing equimolar ratio (1:1) of a $0.2 \mathrm{mM}$ ferric cytb $\mathrm{t}_{5}$ uniformly labeled with ${ }^{13} \mathrm{C},{ }^{2} \mathrm{H}$ and ${ }^{15} \mathrm{~N}$ isotopes and unlabeled ferric cytP450 in a $100 \mathrm{mM}$ KPi buffer at $\mathrm{pH} 7.4,150 \mathrm{mM}$ DPC, $5 \%$ glycerol and $10 \% \mathrm{D}_{2} \mathrm{O}$ at $25^{\circ} \mathrm{C}$ was used in all NMR experiments. $2 \mathrm{D}^{1} \mathrm{H} /{ }^{15} \mathrm{~N}$ SOFAST-HMQC spectra were obtained to test the stability of micelles containing the complex as a function of time. These experiments revealed that the sample was stable for about 28 hours, and started to change after that as indicated by the appearance of multiple peaks and changes in the chemical shift frequency of resonances. We carried out CSA measurements for only those residues for which the chemical shift values did not change even after the completion of measurements. All measurements were carried out on a Bruker $900 \mathrm{MHz}$ NMR spectrometer operating with ${ }^{1} \mathrm{H}$ and ${ }^{15} \mathrm{~N}$ resonance frequencies of 899.799 and $91.186 \mathrm{MHz}$, respectively, using a cryoprobe.

\section{Backbone amide- ${ }^{15} \mathrm{~N}$ relaxation measurements}

The amide- ${ }^{15} \mathrm{~N}$ transverse relaxation rate $\left(R_{2}\right)$ measurments were performed on a full-length $\mathrm{U}_{-}{ }^{15} \mathrm{~N},{ }^{13} \mathrm{C},{ }^{2} \mathrm{H}$ labeled cytb ${ }_{5}$ in the cytb 5 -cytP450 complex incorporated in DPC micelles. We collected a time series of ${ }^{15} \mathrm{~N}$ HSQC spectra for the determination of ${ }^{15} \mathrm{~N}$ transverse spin-spin relaxation time $\left(T_{2}\right) . T_{2}$ measurements were achieved by Carr-Purcell MeiboomGill (CPMG $)^{73}$ spin-echo experiments with relaxation delays of 7.2, 14.4, 28.8, 43.2, 72.0, $100.8,115.2$ and $158.4 \mathrm{~ms}$ (with duplicate points for 14.4 and $43.2 \mathrm{~ms}$ ). In the CPMG pulse sequence, the delays between the $180^{\circ}$ pulses were set to $0.9 \mathrm{~ms}$. $256 t_{1}$ increments were used to obtain $2048 \times 256$ complex data points with 24 scans, 16 dummy scans and 1 s recycle delay; duplicate points for two of the relaxation delays were recorded for estimation of errors.

The amide- ${ }^{15} \mathrm{~N}$ transverse cross-correlated rate $\left(\eta_{x y}\right)$ measurements were accomplished by using proton coupled ${ }^{1} \mathrm{H} /{ }^{15} \mathrm{~N}$ HSQC-IPAP experiments. ${ }^{53,56}$ The IPAP spectra were 
collected in an interleaved manner as pseudo-3D experiments with first 2D-plane corresponding to in-phase (IP) and second plane to anti-phase (AP) spectra. The relaxation delay $\left(\Delta=1 / 2 J_{\mathrm{N}-\mathrm{H}}\right.$, with $J_{\mathrm{N}-\mathrm{H}}$ representing one bond scalar coupling) values were set to $10.64,15.96,21.28,26.60$ and $31.92 \mathrm{~ms}$. The same number of scans was used for the inphase and anti-phase experiments for a given relaxation delay, while it was varied from 96 for the smallest delay to 368 for the largest delay to compensate for the loss of signal intensity due to a large relaxation delay in the IPAP pulse sequence. NMRpipe ${ }^{74}$ was used for NMR data processing and the subsequent addition/subtraction of in-phase and anti-phase spectra, whereas peak assignments were done using Sparky. ${ }^{75}$

\section{Results and discussion}

$\mathrm{Cytb}_{5}$ is a $16.7-\mathrm{kDa}$ membrane-bound electron transfer protein consisting of 134 amino acid residues (Figure 1A). It contains a structured $\mathrm{N}$-terminal water-soluble domain (residues 1-90) bound to a paramagnetic heme unit, a transmembrane helical domain (residues 106-126), and an unstructured 14-residue long linker region (residues 91-104) that connects the transmembrane and heme domains. An overlay of $2 \mathrm{D}^{15} \mathrm{~N}-{ }^{1} \mathrm{H}$ TROSY-HSQC spectra of $\mathrm{U}_{-}{ }^{15} \mathrm{~N},{ }^{13} \mathrm{C},{ }^{2} \mathrm{H}$ labeled full-length rabbit cytb $\mathrm{b}_{5}$ - in the absence and the presence of cytP450 - incorporated in perdeuterated DPC detergent micelles at $25^{\circ} \mathrm{C}$ are presented in Figure 2. The well resolved amide-NH resonances from the soluble domain and the linker region of cytb $_{5}$ dominates the ${ }^{15} \mathrm{~N}-{ }^{1} \mathrm{H}$ TROSY-HSQC spectra. Due to fast spin-spin relaxation, resonances from the transmembrane region of the protein were not observed. There are no notable changes in the chemical shift values for amide-NH resonances of cytb 5 upon complexation with cytP450 (Figure 2). The average chemical shift perturbations in the amide-NH resonances observed for the residues of $\mathrm{cytb}_{5}$ as reported in our previous study ${ }^{72}$ was found to be relatively smaller in magnitude $(<0.01 \mathrm{ppm})$ with a wide spread distribution over a large area of cytb $b_{5}$ indicating no prominent change in the tertiary structure of cytb 5 upon binding to cytP450.

\section{Comparison of backbone amide- ${ }^{15} \mathrm{~N}$ transverse relaxation rates for $\mathrm{cytb}_{5}$ in the $\mathrm{cytb}_{5}-$ cytP450 complex}

Amide- ${ }^{15} \mathrm{~N}$ transverse relaxation rates $\left(R_{2}\right)$ for the full-length $\mathrm{U}-{ }^{15} \mathrm{~N},{ }^{13} \mathrm{C},{ }^{2} \mathrm{H}$ labeled cytb ${ }_{5}$

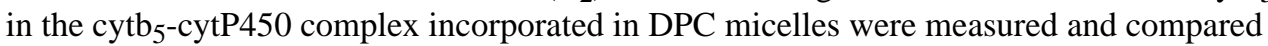
with the values obtained from cytb 5 in the absence of cytP450 (Figure 3). The residues with a fitting error greater than $\sim 18 \%$ are not included in the $R_{2}$ analysis (refer to Table $\mathrm{S} 1$ in the Supporting Information for $R_{2}$ values). The average $R_{2}$ value for a full-length cytb (residues K7-L104) in the complex cytb $5_{5}$-cytP450 is found to be $28.0 \pm 3.4 \mathrm{~s}^{-1}$. The measured $R_{2}$ value for cytb ${ }_{5}$ in the complex is higher than the average $R_{2}$ value $\left(21.6 \pm 1.7 \mathrm{~s}^{-1}\right)$

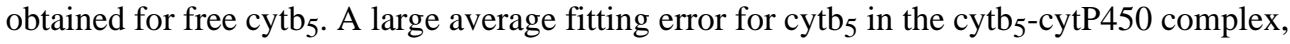
in comparison to free $\mathrm{cytb}_{5}$, is probably due to the formation of a dynamic complex. The

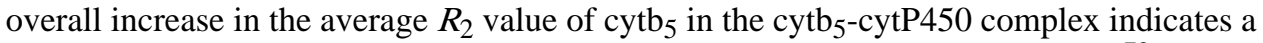
reduced mobility of cytb 5 upon complexation with cytP450. Our previous study, ${ }^{72}$ suggested that the dynamic interaction between cytb ${ }_{5}$ and cytP450 proceed through the formation of many 'encounter complexes', which are often assumed to be only transiently formed; though the encounter complexes may represent a significant fraction of sample population. The driving force behind the formation of these encounter complexes is the long-range electrostatic interaction between the two oppositely charged surfaces (anionic and cationic surfaces of cytb 5 and cytP450, respectively). This conclusion was derived from the small average isotropic chemical shift perturbations observed upon the complex formation. While the populations of cytb ${ }_{5}$ in the free and the bound-state have not been determined in this report, the overall effect of 'transiently formed complexes' is clearly visible from the broadening of NMR signals. NMR line broadening is often described on the basis of an increase in the spin-spin relaxation rate $\left(R_{2}\right)$ of amino-acid residues. The $R_{2}$ rates have 
contributions from molecular motions and/or orientations (described by global correlation time) governed by dipolar coupling and CSA interactions, and chemical exchange between different states. The fraction of encounter complexes between cytb ${ }_{5}$ and cytP450 in the sample would increase the ensemble averaged global correlation time observed for the free cytb $_{5}$. Consequently, transverse relaxation rates $\left(R_{2}\right)$ of cytb in the cytb $_{5}$-cytP450 complex will increase in comparison to the free $\mathrm{cytb}_{5}$; this is clearly reflected from a reduction in the signal intensity in the $2 \mathrm{D}^{15} \mathrm{~N}-{ }^{1} \mathrm{H}$ HSQC spectrum. In addition, the presence of free and the bound states of cytb 5 would also mean a significant chemical exchange between the two states. It is noteworthy to mention here that without the proper quantitative estimation of the free and bound-states of cytb $_{5}$, it is not possible to describe the above effects as minor or major contributions. Relaxation dispersion measurements can reveal the time scale, populations and the chemical shift differences of the species involved in the exchange.

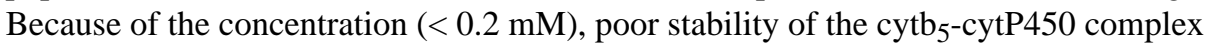
sample and the weak intensity of the signals, such experiments were not attempted.

Based on the $R_{2}$ values, the differential dynamics of N, C-termini, linker region and soluble domain of the full-length cytb 5 upon complexation with cytP450 could be monitered. Nterminal (K7-D8) and the linker region (L92-K94, M96-L99 and T102-D104) residues show significantly smaller $R_{2}$ values $\left(13.9 \mathrm{~s}^{-1}\right.$ and $25.6 \mathrm{~s}^{-1}$ in the complex; $10.5 \mathrm{~s}^{-1}$ and $16.8 \mathrm{~s}^{-1}$ in the free state) in comparison to the compact soluble domain (V9-R89) $R_{2}$ values (29.3 s-1 in the complex and $23.4 \mathrm{~s}^{-1}$ in the free state). This observation suggests a high mobility for the N-terminal residues (small $R_{2}$ values) in comparison to the linker region residues and the rest of the soluble domain of cytb 5 both in the free as well as in the complex samples. In addition, a small average $R_{2}$ value observed for the linker region residues in comparison to the compact soluble doamain of cytb - both in the free and bound states - suggests that residues in this region are more flexible. The small $R_{2}$ values for $\mathrm{N}$-terminal residues are characteristic for the ends of both folded and unfolded proteins. The observed high flexibility of the linker region could be a possible reason for its ability to provide the directional freedom required for an efficient complex formation with its redox partners such as cytP450. It is important to point out that many residues of cytb 5 show a significant increase in $R_{2}$ values upon binding to cytP450 in comparison to free cytb 5 . This could be attributed to the oppositely charged surfaces of the two proteins, which mutually interact to form multiple transient dynamic-encounter complexes as reported. ${ }^{72}$ The residues (K77H85) exhibit a large change in $R_{2}$ values. This could possibly be due to a change in the internal motion for these residues upon binding to cytP450 as they are located near to the more flexible linker region. Similarly, residues (K10, Y12 and L14) located near to highly mobile $\mathrm{N}$-terminal of the cytb $\mathrm{b}_{5}$ in the complex show increased dynamics based on a significant change in $R_{2}$ values. Residues W27-I29 and G56-D58 belonging to two parallel beta-sheets of cytb , wherein the residues are experiencing direct and indirect H-bonding interactions, also show a significant change in $R_{2}$ values in the bound-state of the complex. This is attributed to a change in the orientation of the tryptophan ring of cytb 5 upon complexation with cytP450. Consequently, other residues in close proximity with W27 in parallel beta-sheets are also affected resulting in the observed variation in the $R_{2}$ values.

\section{Measurement of backbone amide- ${ }^{15} \mathrm{~N}$ CSA/dipolar coupling transverse cross-correlated

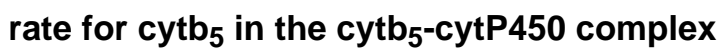

We measured ${ }^{15} \mathrm{~N} \mathrm{CSA} /$ dipolar coupling transverse cross-correlated rates for various residues of cytb $b_{5}$ in the cytb 5 -cytP450 complex using the $2 \mathrm{D}{ }^{1} \mathrm{H} /{ }^{15} \mathrm{~N}$ HSQC type IPAP method as described by Fushman et al. ${ }^{53,56} \mathrm{~A}$ small region with resolved in-phase and antiphase ${ }^{15} \mathrm{~N}$ doublet components of the proton-coupled ${ }^{15} \mathrm{~N}-{ }^{1} \mathrm{H}$ HSQC (IPAP) spectrum are shown in Figure 4. Simplified sum (IP $+a \mathrm{AP})$ and difference (IP+ $a \mathrm{AP})$ spectra were

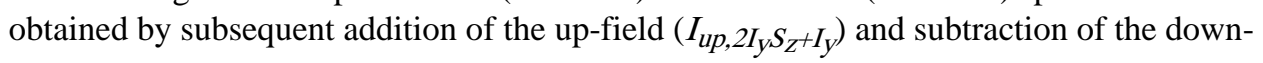


field $\left(I_{d n, 2 I_{y} S_{Z}-I_{y}}\right)$ components of the in-phase and anti-phase doublets, respectively. To compensate for the loss of signal and to obtain a complete removal of unwanted signals, a scaling factor $\alpha=1.2$ was applied to the anti-phase spectrum before its addition or subtraction to the in-phase spectrum.

The transverse cross-correlated rate measurement depends on the ratio of signal intensities of difference (up-field) and sum (down-field) spectra that decays mono exponentially with an increase in the relaxation delay. Nitrogen-15 transverse cross-correlated rates $\left(\eta_{x y}\right)$ were measured by fitting the mono-exponential decay curves to an empirical relation for the

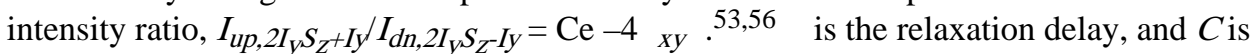
the ratio of signal intensity decay functions associated with up-field and down-field intensities which was kept as a variable along with $\eta_{x y}$ while fitting the curves. Representative decay curves for residues T13, T70 and R73 of cytb 5 in the complex cytb5cytP450 are shown in Figure 5.

\section{Comparison of backbone amide- ${ }^{15} \mathrm{~N}$ CSA/dipolar coupling transverse cross-correlated rates for free and $\mathrm{P} 450$-bound cytb $_{5}$ in micelles}

The backbone amide- ${ }^{15} \mathrm{~N}$ transverse cross-correlated rates $\left(\boldsymbol{\eta}_{\boldsymbol{x} y}\right)$ determined from the bestfitting mono-exponential decay curves for various residues of cytb ${ }_{5}$ in the cytb -cytP450 $^{-}$ complex are plotted in Figure 6 and are compared with the values obtained from free $\mathrm{cytb}_{5}$. We have omitted residues L28, K39, E48, N62 and S76, belonging to the compact soluble domain (V9-R89) of cytb 5 , from further analysis as these residues are associated with a fitting error greater than $\sim 15 \%$ (refer to Table S2 in the Supporting Information for the $\eta_{x y}$ values). The average $\eta_{x y}$ value for the compact soluble domain (V9-H85) of the full-length

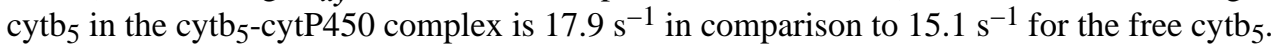
An overall increase in $\eta_{x y}$ values for cytb ${ }_{5}$ in the complex suggests a reduction in the global molecular tumbling as compared to free cytb , which corroborates our results based on $R_{2}$ values. It is important to note here that even if binding of cytb 5 with cytP450 reduces its overall mobility, still different secondary structural elements of the protein complex could undergo differential change in their local motion. This is also obvious from Figure 6 where the change in $\eta_{x y}$ for cytb $b_{5}$ in the complex as compared to free cytb 5 is observed throughout the amino acid chain of the protein suggesting a change in the internal motion of the residues of cytb ${ }_{5}$ upon binding to cytP450. Analogous to free $\mathrm{cytb}_{5}, \eta_{x y}$ values for cytb residues in the complex at the $\mathrm{N}$-terminus (residues 7-9) and the $\mathrm{C}$-terminus (residue 134) are small and fall rapidly indicating a higher mobility in these regions as compared to the structured regions of the protein. The relatively $\eta_{x y}$ values observed for residues at the termini - both in the free as well as cytP450-bound cytb $_{5}$, - also suggest that the binding of cytb $_{5}$ with cytP450 does not significantly change the internal dynamics of cytb 5 residues at the termini. The backbone $\eta_{x y}$ for various residues of cytb $b_{5}$ in the complex correlate well with that obtained for free cytb 5 (Figure 6), barring few exceptions (e.g., H22-I29, F40, A55-D58 and E74-H85). The residues E74-H85 of cytb 5 are located just before the linker region which undergo fast internal motion in the NMR time scale and could possibly bring a change in dynamics for these residues upon binding to cytP450, which is also consistent with results based on $R_{2}$ values. The residue F40 is known to undergo rapid aromatic ring flipping and therefore the observed variation in $\eta_{x y}$ upon complexation with cytP450 could be due to a change in the orientation of its aromatic ring. The residues $\mathrm{H} 22$ and K24 are located in the turn region of cytb 5 and are also involved in the cleft opening as proposed by MD simulations. ${ }^{76}$ Thus, these residues may undergo a different time scale of motion upon complex formation that results in the observed deviation. Residues W27-I29 and G56-D58 belong to parallel beta-sheets, $\beta 2$ and $\beta 4$, respectively, of $\mathrm{cytb}_{5}$. It is possible that the tryptophan ring would have experienced an orientational change upon complex formation leading to the observed deviation in $\eta_{x y}$ values for these residues in comparison to that for 
free cytb 5 . The observed change in $\eta_{x y}$ for these residues of cytb 5 upon complex formation also complement well with the significant variation in $R_{2}$ values (Figure 3 ). In order to understand the overall dynamics in three-dimensional arrangement of cytb ${ }_{5}$ in the cytb $5^{-}$ cytP450 complex with respect to free cytb 5 , we have compared the variation of backbone amide- ${ }^{15} \mathrm{~N}$ transverse cross-correlated rates $\left(\eta_{x y}\right)$ for the structured region such as alphahelices, beta-sheets and turns. It is evident from the standard deviation of the average $\eta_{x y}$ values that there is only a minor variation in $\eta_{x y}$ values for residues in alpha-helix regions (mean $\eta_{x y}$ value, $18.4 \pm 2.4 \mathrm{~s}^{-1}$ and $15.9 \pm 1.7 \mathrm{~s}^{-1}$ for a bound and free cytb ${ }_{5}$, respectively). On the other hand, beta-sheet region (mean $\eta_{x y}$ value, $18.3 \pm 2.8 \mathrm{~s}^{-1}$ and $14.5 \pm 1.1 \mathrm{~s}^{-1}$ for a bound and free cytb $b_{5}$, respectively) and turns (mean $\eta_{x y}$ value, $17.2 \pm 3.3 \mathrm{~s}^{-}$and $14.8 \pm 2.3 \mathrm{~s}^{-1}$ for a bound and free cytb 5 , respectively) of cytb 5 in the complex show an increased variation as compared to free cytb $_{5}$ (Figure S1 in the Supporting Information) suggesting a larger change in dynamics for beta-sheet and turn residues.

\section{Comparison of backbone amide- ${ }^{15} \mathrm{~N}$ CSA for cytb $_{5}$ free and in complex with cytP450 determined using transverse cross correlated rates}

We have implemented a model independent approach proposed by Fushman and Cowburn to determine ${ }^{15}$ N-CSA tensors. ${ }^{77}$ For the calculation of ${ }^{15} \mathrm{~N}$-CSAs, we have used the ratio; $\eta_{x y} / R_{2}=2 d c\left(P_{2}(\cos \beta) /\left(d^{2}+c^{2}\right)\right.$, under the assumption of axially symmetric CSA tensors. In the expression, $d=-\mu_{0} \gamma_{N} \gamma_{H} \hbar / 4 \pi r_{N-H}^{3}$ represents the dipolar coupling constant with $r^{3} \mathrm{~N}-\mathrm{H}$ as the ${ }^{15} \mathrm{~N}-{ }^{1} \mathrm{H}$ bond length and other symbols have their usual meaning. The parameter $c$ represents the CSA constant given by, $c=-\omega_{N}\left(\sigma_{\|}-\sigma_{\perp}\right) / 3$; where $\omega_{N}$ is the Larmor frequency of ${ }^{15} \mathrm{~N}$ nucleus and $\left(\sigma_{\|}-\sigma_{\perp}\right)$ represents the CSA span (the difference between least shielded $\left(\sigma_{\|}\right)$and most shielded $\left(\sigma_{\perp}\right)$ components of CSA tensor). $P_{2}(\cos \beta)$ is the Legendre polynomial with $\beta$ representing the angle between the $\mathrm{N}-\mathrm{H}$ dipolar vector and the least shielded component in the principal axis system of the ${ }^{15} \mathrm{~N}-\mathrm{CSA}$ tensor. As evident from the expression above, the ratio of $\eta_{x y}$ and $R_{2}$ depends only on ${ }^{15} \mathrm{~N}$ CSA tensor and ${ }^{15} \mathrm{~N}-{ }^{1} \mathrm{H}$ dipolar coupling; and is independent of contributions from conformational exchange and high-frequency motions provided the rotational diffusion of the macromolecule is isotropic. It is worthwhile to point out that the possibilities of uncertainty in the assumptions used for the determination of amide- ${ }^{15} \mathrm{~N} \mathrm{CSA}$ will be greater for more mobile regions than for less mobile regions. In the present study, the calculated $\eta_{x y}$ values for various cytb residues in the cytb $_{5}$-cytP450 complex show a linear correlation $\left(R_{2}=\right.$ $(0.61 \pm 0.02) \eta_{x y}$ ) with a uniform spread of data points against $R_{2}$ as shown in Figure 7. It can be seen from the plot that $\eta_{x y}$ and $R_{2}$ do not correlate well for few residues of cytb 5 in the cytb $_{5}$-cytP450 complex. It could be possible that there may be some conformational exchange contributions, between the bound and unbound states of cytb ${ }_{5}$ in the cytb ${ }_{5}$ cytP450 complex, to transverse relaxation rates leading to the observed variation. This is also validated by a substantial increase in $R_{2}$ values for many cytb ${ }_{5}$ residues upon binding to cytP450, in comparison to free cytb ${ }_{5}$, as shown in Figure 3. Using $\eta_{x y}$ and $R_{2}$ values, backbone amide- ${ }^{15} \mathrm{~N}$ CSA $\left(\sigma_{\|}-\sigma_{\perp}\right)$ spans for cytb ${ }_{5}$ in the cytb ${ }_{5}$-cytP450 complex were determined (refer to Table S3 in the Supporting Information for the CSA values) and compared with the values determined for free cytb ${ }_{5}$ (Figure 8). The calculations were performed by assuming an effective ${ }^{15} \mathrm{~N}-{ }^{1} \mathrm{H}$ bond length, $r_{\mathrm{N}-\mathrm{H}}$, of $1.023 \AA$ and $\beta=18^{\circ}$ (the angle between the $\mathrm{N}-\mathrm{H}$ bond and the least shielded component of ${ }^{15} \mathrm{~N}$ CSA tensor).

Based on the small transverse cross-correlated rate $\left(\eta_{x y}\right)$ and transverse relaxation rate $\left(R_{2}\right)$ values observed for the residues K7, D8 and D134 at the termini (Figure 7), these residues were not included in our further analysis as they undergo high-frequency motion (ps-ns rotational correlation time) and, therefore, the experimentally determined CSA tensors for these residues may become time-dependent. ${ }^{44,60} \mathrm{We}$ have also omitted a turn residue T13 and a helix residue E43 from our further analysis as they show substantial deviation in the 
correlation plot (Figure 7); we believe these residues may undergo a significant conformational exchange as a result the measured CSA values may be inaccurate. The overall mean value of backbone amide- ${ }^{15} \mathrm{~N}$ CSA, excluding the outliers at the termini and turns for cytb $\mathrm{b}_{5}$ in the cytb $\mathrm{c}_{5}$-cytP450 complex, was found to be equal to $-165.5 \mathrm{ppm}$ which is nearly similar to the mean value of $-171.7 \mathrm{ppm}$ obtained for free cytb 5 .

Since amide- $-{ }^{15} \mathrm{~N}$ CSA is extremely sensitive to electrostatic interaction and protein-protein interaction can significantly alter the electronic environment for residues in the interacting interface, significant changes in the CSA span due to cytP450-cytb interaction were observed in this study (Figure 8). Our previous study confirmed that there is no significant

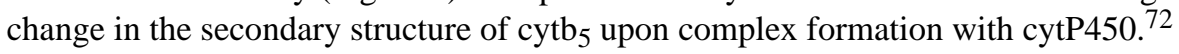

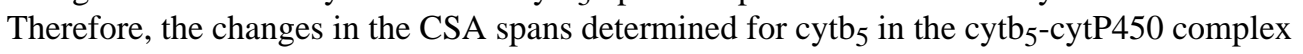
in this study can be attributed to changes in the electronic environment (mainly due to the formation of many transient state encounter complexes) and alteration in the dynamics of cytb $_{5}$. Our results show a larger change in the CSA span for residues E49, V50, F63, E64, D65, G67, T70, A72, R73 and E74 that have been found to be in the interacting interface of the cytb ${ }_{5}$-cytP450 complex as reported elsewhere. ${ }^{72}$ The fact that the ${ }^{15} \mathrm{~N}$-CSA span for some of these residues (V50, G67, R73 and E74) is reduced and increased for others (E64, D65 and T70) on complexation with cytP450 suggest that a change in the dynamics of cytb 5 alone is unlikely to be a major contributor to the observed changes in the CSA spans. This is further confirmed by the observation that some of the residues (such as E49, F63 and A72) exhibit a smaller change $(< \pm 15 \mathrm{ppm})$ in ${ }^{15} \mathrm{~N}-\mathrm{CSA}$ span as compared to free cytb $b_{5}$. In addition, one of these residues D65 exhibiting a significant increase in the CSA span in the present study has been found to be involved in the H-bonding interaction and salt bridges formation with R122 and K433 of cytP450. ${ }^{72}$ Our site-directed mutagenesis data also identified less significant role in protein-protein interactions for cytb 5 residues E49 and E42 that also seen to have undergone a smaller change in CSA upon binding to cytP450.

The beta-sheet residues (K10, Y12) and the turn residues (D36, H85) of cytb $b_{5}$ in the complex show a larger change in ${ }^{15} \mathrm{~N}$ CSA span when compared to free cytb 5 even though the ${ }^{15} \mathrm{~N}$ transverse cross-correlated rates are nearly similar for these residues in the complex and free cytb ${ }_{5}$. The observed large change in ${ }^{15} \mathrm{~N}$ CSA for these residues is accounted on the basis of CSA dependence on transverse relaxation rate $\left(R_{2}\right)$ apart from transverse crosscorrelated rate $\left(\eta_{x y}\right)$, internuclear distance $\left(I_{\mathrm{N}-\mathrm{H}}\right)$ and angle $(\beta)$. In the present analysis, amide- $-{ }^{15} \mathrm{~N}$ CSA could be extracted for only those residues that are independent of exchange contribution and high-frequency (ps-ns timescale) motions as pointed out earlier. Therefore, in the presence of any internal motion both $R_{2}$ and $\eta_{x y}$ should be affected equally. However, these residues in the cytb ${ }_{5}$-cytP450 complex $\left(R_{2}=28.0,30.2,31.7\right.$ and $31.4 \mathrm{~s}^{-1}$ for K10, Y12, D36 and H85, respectively; see Table S1 in the Supporting Information for the $R_{2}$ values) show a large change in backbone amide- ${ }^{15} \mathrm{~N}$ transverse relaxation rates as compared to free $\operatorname{cytb}_{5}\left(R_{2}=19.8,22.1,22.7\right.$ and $24.1 \mathrm{~s}^{-1}$ for K10, Y12, D36 and H85, respectively); and as a consequence, we obtained a large change in backbone amide- ${ }^{15} \mathrm{~N}$ CSA for these residues. It is interesting to note that phenylalanine residues F40 and F79 of cytb

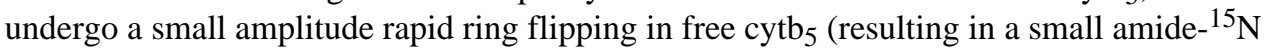
CSA value), become more rigid upon complex formation as indicated by the large change in amide- ${ }^{15} \mathrm{~N}$ CSA. On the other hand, W27 that is rigid (high amide- ${ }^{15} \mathrm{~N}$ CSA value) in free cytb $_{5}$ may seem to undergo certain change in its orientation upon interacting with cytP450 as shown by a reduced amide- ${ }^{15} \mathrm{~N}$ CSA value. Residues H22 and K24 belonging to a1- $\beta 2$ loop of cytb 5 undergo a substantial change in amide- ${ }^{15} \mathrm{~N} \mathrm{CSA}$ in the cytb ${ }_{5}-\mathrm{cytP} 450$ complex in comparison to free cytb ${ }_{5}$. Both these residues are involved in the cleft opening ${ }^{76}$ on top of cytb $b_{5}$ and hence are believed to undergo a change in internal dynamics and orientation upon complexation. 
Since backbone amide- ${ }^{15} \mathrm{~N}$ CSA tensors are sensitive to internal and overall motions of the protein, a difference in the variation of CSA spans for the structured elements such as alphahelices, beta-sheets and turns may be attributed to the difference in their dynamics in the

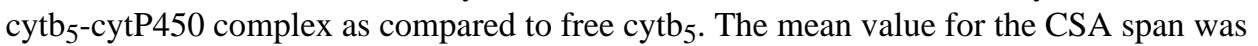
found to be larger in the helical region $(-184.5 \mathrm{ppm})$ than in the beta-sheet $(-146.8 \mathrm{ppm})$ and turns $(-146.2 \mathrm{ppm})$ excluding the outliers in the termini. The higher mean value of ${ }^{15} \mathrm{~N}$ CSA span for the helical region in the cytb-cytP450 complex, as compared to the overall average of the protein, confirms our earlier results on free $\operatorname{cytb}_{5}\left(\sigma_{\|}-\sigma_{\perp}=-186.2 \mathrm{ppm}\right)$ that was supposed to be due to an additional contribution from CSA and dipolar shielding anisotropy (DSA) cross-correlated interaction $(\mathrm{CSA} \times \mathrm{DSA}) .{ }^{78,79}$ This contribution originates from the interaction of backbone amide protons and nitrogens, that are in close proximity with the thermally averaged electronic spin (Curie spin) ${ }^{80,81}$ of spin $(S=1 / 2)$ paramagnetic center $(\mathrm{Fe}(\mathrm{III}))$ of $\mathrm{cytb}_{5}$, causing a change in the ${ }^{15} \mathrm{~N}$-transverse relaxation rates. The paramagnetic effect was found to be stronger due to an increase in the relaxation rate for amide protons and nitrogens in close proximity to the heme unit. ${ }^{82}$ The mean CSA values of beta-sheet and

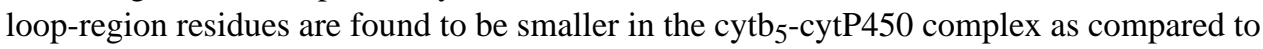
beta sheet $\left(\sigma_{\|}-\sigma_{\perp}=-166.0 \mathrm{ppm}\right)$ and loop region residues $\left(\sigma_{\|}-\sigma_{\perp}=-161.1 \mathrm{ppm}\right)$ in free

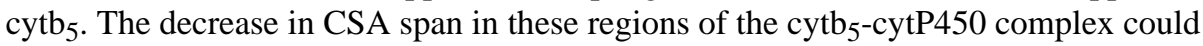
suggest a change in local motion in these regions of cytb 5 when it binds to cytP450 as compared to free $\mathrm{cytb}_{5}$.

\section{Conclusion}

In summary, we have measured ${ }^{15} \mathrm{~N} \mathrm{CSA}$ /dipolar coupling transverse cross-correlated rates using ${ }^{1} \mathrm{H}$-coupled ${ }^{15} \mathrm{~N}-{ }^{1} \mathrm{H}$ HSQC type IPAP spectra to determine ${ }^{15} \mathrm{~N}$ CSA tensors for a fulllength membrane-bound rabbit cytb $b_{5}$ in the cytb ${ }_{5}$-cytP4502B4 complex incorporated in DPC micelles. We have compared the CSA values with our earlier reported values for cytb 5 incorporated in DPC micelles to provide insights into protein-protein interactions. ${ }^{52}$ The measured ${ }^{15} \mathrm{~N}$ transverse cross-correlated rates suggest a larger change in dynamics of betasheet and turn residues of cytb $b_{5}$ in the complex as compared to free cytb ${ }_{5}$. The overall mean value of amide- ${ }^{15} \mathrm{~N} \mathrm{CSA}$, excluding the outliers at termini and turns, for cytb ${ }_{5}$ in the cytb ${ }_{5}-$ cytP450 complex was found to be equal to $-165.6 \mathrm{ppm}$ for an NH bond length of $1.023 \AA$ and at $\beta=18^{\circ}$; this value is similar to the mean value of $-171.7 \mathrm{ppm}$ determined for free cytb $_{5}$. The observed variation in ${ }^{15} \mathrm{~N}$ CSA throughout the amino acid chain of cytb $\mathrm{b}_{5}$ in the cytb $_{5}$-cytP450 complex validates the formation of many transient state dynamic encounter complexes formed between the oppositely charged surfaces of cytb 5 and cytP450. The amide- ${ }^{15} \mathrm{~N}$ CSA change for various residues located at the interaction interface of cytb 5 cytP450 complex correlates well with the recently reported structure of the complex.72,83 The average values of ${ }^{15} \mathrm{~N}$ CSA for residues in the helical regions of cytb $b_{5}$ in the complex was found to be $-184.5 \mathrm{ppm}$, which is consistent with the value reported for free cytb 5 .

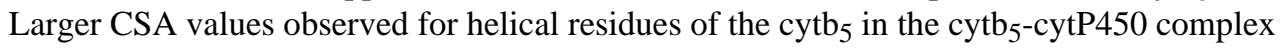
could possibly be due to the enhanced CSA/DSA cross-correlated rate resulting from the interaction of amide nitrogens and protons with the paramagnetic center $\mathrm{Fe}(\mathrm{III})$ of the heme as proposed earlier. We believe that the results presented in this study could pave avenues to utilize CSA tensors in the structural studies of protein-protein and protein-ligand interactions. ${ }^{84}$ In addition, the use of well characterized CSA tensors could be significant in the structural studies of metalloproteins by solid-state NMR spectroscopy. ${ }^{85-87}$

\section{Supplementary Material}

Refer to Web version on PubMed Central for supplementary material. 


\section{Acknowledgments}

This research is supported by funds from NIH (GM084018 and GM095640 to A.R.). We thank Dr. Kazutoshi Yamamoto for providing a model representation of the membrane-bound cytP450-cytb5 complex shown in Figure 1(B).

\section{References}

1. Wylie BJ, Sperling LJ, Nieuwkoop AJ, Franks WT, Oldfield E, Rienstra CM. Ultrahigh Resolution Protein Structures Using NMR Chemical Shift Tensors. Proc. Natl. Acad. Sci. U S A. 2011; 108:16974-16979. [PubMed: 21969532]

2. Shen Y, Lange O, Delaglio F, Rossi P, Aramini JM, Liu G, Eletsky A, Wu Y, Singarapu KK, Lemak A, Ignatchenko A, Arrowsmith CH, Szyperski T, Montelione GT, Baker D, Bax A. Consistent Blind Protein Structure Generation from NMR Chemical Shift Data. Proc. Natl. Acad. Sci. U S A. 2008; 105:4685-4690. [PubMed: 18326625]

3. Shen Y, Vernon R, Baker D, Bax A. De Novo Protein Structure Generation from Incomplete Chemical Shift Assignments. J. Biomol. NMR. 2009; 43:63-78. [PubMed: 19034676]

4. Lipsitz RS, Tjandra N. 15N Chemical Shift Anisotropy in Protein Structure Refinement and Comparison with NH Residual Dipolar Couplings. J. Magn. Reson. 2003; 164:171-176. [PubMed: 12932470]

5. Robustelli P, Stafford KA, Palmer AG 3rd. Interpreting Protein Structural Dynamics from NMR Chemical Shifts. J. Am. Chem. Soc. 2012; 134:6365-6374. [PubMed: 22381384]

6. Cornilescu G, Delaglio F, Bax A. Protein Backbone Angle Restraints from Searching a Database for Chemical Shift and Sequence Homology. J. Biomol. NMR. 1999; 13:289-302. [PubMed: 10212987]

7. Pandey MK, Ramamoorthy A. Quantum Chemical Calculations of Amide- ${ }^{15} \mathrm{~N}$ Chemical Shift Anisotropy Tensors for a Membrane-Bound Cytochrome-b5. J. Phys. Chem. B. 2013; 117:859-867. [PubMed: 23268659]

8. Birn J, Poon A, Mao Y, Ramamoorthy A. Ab Initio Study of ${ }^{13} \mathrm{Ca}$ Chemical Shift Anisotropy Tensors in Peptides. J. Am. Chem. Soc. 2004; 126:8529-8534. [PubMed: 15238010]

9. Brender JR, Taylor DM, Ramamoorthy A. Orientation of Amide-Nitrogen-15 Chemical Shift Tensors in Peptides: A Quantum Chemical Study. J. Am. Chem. Soc. 2001; 123:914-922. [PubMed: 11456625]

10. Poon A, Birn J, Ramamoorthy A. How Does an Amide- ${ }^{15} \mathrm{~N}$ Chemical Shift Tensor Vary in Peptides? J. Phys. Chem. B. 2004; 108:16577-16585. [PubMed: 18449362]

11. Oldfield E. Quantum Chemical Studies of Protein Structure. Philos. Trans. R. Soc. Lond. B Biol. Sci. 2005; 360:1347-1361. [PubMed: 16147526]

12. Oldfield E. Chemical Shifts in Amino Acids, Peptides, and Proteins: From Quantum Chemistry to Drug Design. Ann. Rev. Phys. Chem. 2002; 53:349-378. [PubMed: 11972012]

13. Dedios AC, Pearson JG, Oldfield E. Secondary and Tertiary Structural Effects on Protein NMR Chemical-Shifts - an Ab initio Approach. Science. 1993; 260:1491-1496. [PubMed: 8502992]

14. Cai L, Fushman D, Kosov DS. Density Functional Calculations of Chemical Shielding of Backbone ${ }^{15} \mathrm{~N}$ in Helical Residues of Protein G. J. Biomol. NMR. 2009; 45:245-253. [PubMed: 19644655]

15. Cai L, Fushman D, Kosov DS. Density Functional Calculations of ${ }^{15} \mathrm{~N}$ Chemical Shifts in Solvated Dipeptides. J. Biomol. NMR. 2008; 41:77-88. [PubMed: 18484179]

16. Cai L, Kosov DS, Fushman D. Density Functional Calculations of Backbone ${ }^{15} \mathrm{~N}$ Shielding Tensors in Beta-Sheet and Turn Residues of Protein G. J. Biomol. NMR. 2011; 50:19-33. [PubMed: 21305337]

17. Le HB, Oldfield E. Ab Initio Studies of Amide- ${ }^{15} \mathrm{~N}$ Chemical Shifts in Dipeptides: Applications to Protein NMR Spectroscopy. J. Phys. Chem. 1996; 100:16423-16428.

18. Tang S, Case DA. Calculation of Chemical Shift Anisotropy in Proteins. J. Biomol. NMR. 2011; 51:303-312. [PubMed: 21866436] 
19. Strohmeier M, Grant DM. Experimental and Theoretical Investigation of the ${ }^{13} \mathrm{C}$ and ${ }^{15} \mathrm{~N}$ Chemical Shift Tensors in Melanostatin-Exploring the Chemical Shift Tensor as a Structural Probe. J. Am. Chem. Soc. 2004; 126:966-977. [PubMed: 14733574]

20. Case DA. Calculations of NMR Dipolar Coupling Strengths in Model Peptides. J. Biomol. NMR. 1999; 15:95-102. [PubMed: 10605083]

21. Frank A, Moller HM, Exner TE. Toward the Quantum Chemical Calculation of NMR Chemical Shifts of Proteins. 2. Level of Theory, Basis Set, and Solvents Model Dependence. J. Chem. Theo. Comp. 2012; 8:1480-1492.

22. Frank A, Onila I, Moller HM, Exner TE. Toward the Quantum Chemical Calculation of Nuclear Magnetic Resonance Chemical Shifts of Proteins. Prot.-Struc. Func. Bioinform. 2011; 79:2189_ 2202.

23. Emmer J, Vavrinska A, Sychrovsky V, Benda L, Kriz Z, Koca J, Boelens R, Sklenar V, Trantirek L. Influence of the O-Phosphorylation of Serine, Threonine and Tyrosine in Proteins on the Amidic ${ }^{15}$ N Chemical Shielding Anisotropy Tensors. J. Biomol. NMR. 2013; 55:59-70. [PubMed: 23202985]

24. Saito H, Ando I, Ramamoorthy A. Chemical Shift Tensor - the Heart of NMR: Insights into Biological Aspects of Proteins. Prog. Nucl. Mag. Res. Sp. 2010; 57:181-228.

25. Hartzell CJ, Whitfield M, Oas TG, Drobny GP. Determination of the ${ }^{15} \mathrm{~N}$ and ${ }^{13} \mathrm{C}$ Chemical-Shift Tensors of L- $\left[{ }^{13} \mathrm{C}\right]$ Alanyl-L- $\left[{ }^{15} \mathrm{~N}\right]$ Alanine from the Dipole-Coupled Powder Patterns. J. Am. Chem. Soc. 1987; 109:5966-5969.

26. Oas TG, Hartzell CJ, Dahlquist FW, Drobny GP. The Amide ${ }^{15} \mathrm{~N}$ Chemical-Shift Tensors of four Peptides Determined from ${ }^{13} \mathrm{C}$ Dipole-Coupled Chemical-Shift Powder Patterns. J. Am. Chem. Soc. 1987; 109:5962-5966.

27. Oas TG, Hartzell CJ, Mcmahon TJ, Drobny GP, Dahlquist FW. The Carbonyl ${ }^{13} \mathrm{C}$ Chemical-Shift Tensors of five Peptides Determined from ${ }^{15} \mathrm{~N}$ Dipole-Coupled Chemical-Shift Powder Patterns. J. Am. Chem. Soc. 1987; 109:5956-5962.

28. Durr UH, Gildenberg M, Ramamoorthy A. The Magic of Bicelles Lights up Membrane Protein Structure. Chem. Rev. 2012; 112:6054-6074. [PubMed: 22920148]

29. Hester RK, Ackerman JL, Neff BL, Waugh JS. Separated Local Field Spectra in NMR Determination of Structure of Solids. Phys. Rev. Lett. 1976; 36:1081-1083.

30. Wu CH, Ramamoorthy A, Opella SJ. High-Resolution Heteronuclear Dipolar Solid-State NMRSpectroscopy. J. Magn. Reson. Ser. A. 1994; 109:270-272.

31. Ramamoorthy A, Opella SJ. 2-Dimensional Chemical-Shift Heteronuclear Dipolar Coupling Spectra Obtained with Polarization Inversion Spin-Exchange at the Magic- Angle and MagicAngle Sample-Spinning (Pisemamas). Solid State Nucl. Mag. 1995; 4:387-392.

32. Wylie BJ, Franks WT, Rienstra CM. Determinations of ${ }^{15} \mathrm{~N}$ Chemical Shift Anisotropy Magnitudes in a Uniformly ${ }^{15} \mathrm{~N},{ }^{13} \mathrm{C}$-Labeled Microcrystalline Protein by Three-Dimensional Magic-Angle Spinning Nuclear Magnetic Resonance Spectroscopy. J. Phys. Chem. B. 2006; 110:10926-10936. [PubMed: 16771346]

33. Wylie BJ, Franks WT, Graesser DT, Rienstra CM. Site-Specific ${ }^{13} \mathrm{C}$ Chemical Shift Anisotropy Measurements in a Uniformly ${ }^{15} \mathrm{~N},{ }^{13} \mathrm{C}$-Labeled Microcrystalline Protein by 3D Magic-Angle Spinning NMR Spectroscopy. J. Am. Chem. Soc. 2005; 127:11946-11947. [PubMed: 16117526]

34. Maricq MM, Waugh JS. NMR in Rotating Solids. J. Chem. Phys. 1979; 70:3300-3316.

35. Wylie BJ, Sperling LJ, Frericks HL, Shah GJ, Franks WT, Rienstra CM. Chemical-Shift Anisotropy Measurements of Amide and Carbonyl Resonances in a Microcrystalline Protein with S Magic-Angle Spinning NMR Spectroscopy. J. Am. Chem. Soc. 2007; 129:5318-5319. [PubMed: 17425317]

36. Chan JCC, Tycko R. Recoupling of Chemical Shift Anisotropies in Solid- State NMR under HighSpeed Magic-Angle Spinning and in Uniformly ${ }^{13}$ C-labeled systems. J. Chem. Phys. 2003; 118:8378-8389.

37. Yao X, Hong M. Determination of Ca Chemical Shift Tensor Orientation in Peptides by DipolarModulated Chemical Shift Recoupling NMR Spectroscopy. J. Am. Chem. Soc. 2002; 124:2730 2738. [PubMed: 11890824] 
38. Shekar SC, Ramamoorthy A, Wittebort RJ. Determination of the Chemical Shielding Tensor Orientation from Two or One of the Three Conventional Rotations of a Single Crystal. J. Magn. Reson. 2002; 155:257-262. [PubMed: 12036337]

39. Tjandra N, Kuboniwa H, Ren H, Bax A. Rotational Dynamics of Calcium-Free Calmodulin Studied by ${ }^{15}$ N-NMR Relaxation Measurements. Eur. J. Biochem. 1995; 230:1014-1024. [PubMed: 7601131]

40. Damberg P, Jarvet J, Allard P, Graslund A. Quantitative Estimation of Magnitude and Orientation of the CSA Tensor from Field Dependence of Longitudinal NMR Relaxation Rates. J. Biomol. NMR. 1999; 15:27-37. [PubMed: 20703961]

41. Damberg P, Jarvet J, Graslund A. Limited Variations in ${ }^{15}$ N CSA Magnitudes and Orientations in Ubiquitin Are Revealed by Joint Analysis of Longitudinal and Transverse NMR Relaxation. J. Am. Chem. Soc. 2005; 127:1995-2005. [PubMed: 15701036]

42. Hall JB, Fushman D. Variability of the ${ }^{15} \mathrm{~N}$ Chemical Shielding Tensors in the B3 Domain of Protein $\mathrm{G}$ from ${ }^{15} \mathrm{~N}$ Relaxation Measurements at Several Fields. Implications for Backbone Order Parameters. J. Am. Chem. Soc. 2006; 128:7855-7870. [PubMed: 16771499]

43. Canet D, Barthe P, Mutzenhardt P, Roumestand C. A Comprehensive Analysis of Multifield ${ }^{15} \mathrm{~N}$ Relaxation Parameters in Proteins: Determination of ${ }^{15} \mathrm{~N}$ Chemical Shift Anisotropies. J. Am. Chem. Soc. 2001; 123:4567-4576. [PubMed: 11457243]

44. Kroenke CD, Rance M, Palmer AG. Variability of the ${ }^{15} \mathrm{~N}$ Chemical Shift Anisotropy in Escherichia Coli Ribonuclease H in Solution. J. Am. Chem. Soc. 1999; 121:10119-10125.

45. Cisnetti F, Loth K, Pelupessy P, Bodenhausen G. Determination of Chemical Shift Anisotropy Tensors of Carbonyl Nuclei in Proteins through Cross-Correlated Relaxation in NMR. Chem. Phys. Chem. 2004; 5:807-814. [PubMed: 15253308]

46. Loth K, Pelupessy P, Bodenhausen G. Chemical Shift Anisotropy Tensors of Carbonyl, Nitrogen, and Amide Proton Nuclei in Proteins through Cross-Correlated Relaxation in NMR Spectroscopy. J. Am. Chem. Soc. 2005; 127:6062-6068. [PubMed: 15839707]

47. Fruh D, Chiarparin E, Pelupessy P, Bodenhausen G. Measurement of Long-Range CrossCorrelation Rates Using a Combination of Single- and Multiple-Quantum NMR Spectroscopy in One Experiment. J. Am. Chem. Soc. 2002; 124:4050-4057. [PubMed: 11942843]

48. Ying JF, Grishaev A, Bryce DL, Bax A. Chemical Shift Tensors of Protonated Base Carbons in Helical RNA and DNA from NMR Relaxation and Liquid Crystal Measurements. J. Am. Chem. Soc. 2006; 128:11443-11454. [PubMed: 16939267]

49. Cornilescu G, Bax A. Measurement of Proton, Nitrogen, and Carbonyl Chemical Shielding Anisotropies in a Protein Dissolved in a Dilute Liquid Crystalline Phase. J. Am. Chem. Soc. 2000; 122:10143-10154.

50. Goldman M. Interference Effects in the Relaxation of a Pair of Unlike Spin-1/2 Nuclei. J. Magn. Reson. 1984; 60:437-452.

51. Lienin SF, Bremi T, Brutscher B, Bruschweiler R, Ernst RR. Anisotropic Intramolecular Backbone Dynamics of Ubiquitin Characterized by NMR Relaxation and MD Computer Simulation. J. Am. Chem. Soc. 1998; 120:9870-9879.

52. Pandey MK, Vivekanandan S, Ahuja S, Pichumani K, Im SC, Waskell L, Ramamoorthy A. Determination of ${ }^{15} \mathrm{~N}$ Chemical Shift Anisotropy from a Membrane-Bound Protein by NMR Spectroscopy. J. Phys. Chem. B. 2012; 116:7181-7189. [PubMed: 22620865]

53. Hall JB, Fushman D. Direct Measurement of the Transverse and Longitudinal ${ }^{15} \mathrm{~N}$ Chemical Shift Anisotropy-Dipolar Cross-Correlation Rate Constants Using ${ }^{1} \mathrm{H}-\mathrm{Coupled}$ HSQC Spectra. Magn. Reson. Chem. 2003; 41:837-842.

54. Fushman D, Tjandra N, Cowburn D. Direct Measurement of ${ }^{15} \mathrm{~N}$ Chemical Shift Anisotropy in Solution. J. Am. Chem. Soc. 1998; 120:10947-10952.

55. Fushman D, Tjandra N, Cowburn D. An Approach to Direct Determination of Protein Dynamics from ${ }^{15} \mathrm{~N}$ NMR Relaxation at Multiple Fields, Independent of Variable ${ }^{15} \mathrm{~N}$ Chemical Shift Anisotropy and Chemical Exchange Contributions. J. Am. Chem. Soc. 1999; 121:8577-8582.

56. Hall JB, Dayie KT, Fushman D. Direct Measurement of the ${ }^{15} \mathrm{~N}$ CSA/Dipolar Relaxation Interference from Coupled HSQC Spectra. J. Biomol. NMR. 2003; 26:181-186. [PubMed: 12766413] 
57. Lakomek NA, Kaufman JD, Stahl SJ, Louis JM, Grishaev A, Wingfield PT, Bax A. Internal Dynamics of the Homotrimeric HIV-1 Viral Coat Protein Gp41 on Multiple Time Scales. Angew. Chem. Int. Ed. Engl. 2013; 52:3911-3915. [PubMed: 23450638]

58. Meirovitch E, Shapiro YE, Zerbetto M, Polimeno A. SRLS Analysis of ${ }^{15} \mathrm{~N}$ Spin Relaxation from E. Coil Ribonuclease HI: The Tensorial Perspective. J. Phys. Chem. B. 2012; 116:886-894. [PubMed: 22126306]

59. Zerbetto M, Anderson R, Bouguet-Bonnet S, Rech M, Zhang LQ, Meirovitch E, Polimeno A, Buck M. Analysis of ${ }^{15} \mathrm{~N}-{ }^{1} \mathrm{H}$ NMR Relaxation in Proteins by a Combined Experimental and Molecular Dynamics Simulation Approach: Picosecond-Nanosecond Dynamics of the Rho Gtpase Binding Domain of Plexin-B1 in the Dimeric State Indicates Allosteric Pathways. J. Phys. Chem. B. 2013; 117:174-184. [PubMed: 23214953]

60. Scheurer C, Skrynnikov NR, Lienin SF, Straus SK, Bruschweiler R, Ernst RR. Effects of Dynamics and Environment on ${ }^{15} \mathrm{~N}$ Chemical Shielding Anisotropy in Proteins. A Combination of Density Functional Theory, Molecular Dynamics Simulation, and Nmr Relaxation. J. Am. Chem. Soc. 1999; 121:4242-4251.

61. Ferraro MB, Repetto V, Facelli JC. Modeling NMR Chemical Shifts: A Comparison of Charge Models for Solid State Effects on ${ }^{15} \mathrm{~N}$ Chemical Shift Tensors. Solid State Nucl. Mag. 1998; 10:185-189.

62. Wei Y, de Dios AC, McDermott AE. Solid-State ${ }^{15}$ N NMR Chemical Shift Anisotropy of Histidines: Experimental and Theoretical Studies of Hydrogen Bonding. J. Am. Chem. Soc. 1999; 121:10389-10394.

63. Hu JZ, Facelli JC, Alderman DW, Pugmire RJ, Grant DM. ${ }^{15} \mathrm{~N}$ Chemical Shift Tensors in Nucleic Acid Bases. J. Am. Chem. Soc. 1998; 120:9863-9869.

64. Ramamoorthy A, Wu CH, Opella SJ. Magnitudes and Orientations of the Principal Elements of the $\mathrm{H}-1$ Chemical Shift, ${ }^{1} \mathrm{H}_{-}{ }^{15} \mathrm{~N}$ Dipolar Coupling, and ${ }^{15} \mathrm{~N}$ Chemical Shift Interaction Tensors in ${ }^{15} \mathrm{~N}(\epsilon 1)$-Tryptophan and ${ }^{15} \mathrm{~N}(\pi)$-Histidine Side Chains Determined by Three-Dimensional SolidState NMR Spectroscopy of Polycrystalline Samples. J. Am. Chem. Soc. 1997; 119:10479-10486.

65. Sitkoff D, Case DA. Theories of Chemical Shift Anisotropies in Proteins and Nucleic Acids. Prog. Nucl. Mag. Res. Sp. 1998; 32:165-190.

66. Walling AE, Pargas RE, deDios AC. Chemical Shift Tensors in Peptides: A Quantum Mechanical Study. J. Phys. Chem. A. 1997; 101:7299-7303.

67. Zhu T, He X, Zhang JZH. Fragment Density Functional Theory Calculation of NMR Chemical Shifts for Proteins with Implicit Solvation. Phys. Chem. Chem. Phys. 2012; 14:7837-7845. [PubMed: 22314755]

68. Yamamoto K, Durr UHN, Xu JD, Im SC, Waskell L, Ramamoorthy A. Dynamic Interaction between Membrane-Bound Full-Length Cytochrome P450 and Cytochrome $\mathrm{b}_{5}$ Observed by SolidState NMR Spectroscopy. Sci. Rep. 2013; 3:2538. [PubMed: 23985776]

69. Yamamoto K, Gildenberg M, Ahuja S, Im SC, Pearcy P, Waskell L, Ramamoorthy A. Probing the Transmembrane Structure and Topology of Microsomal Cytochrome-P450 by Solid-State NMR on Temperature-Resistant Bicelles. Sci. Rep. 2013; 3:2556. [PubMed: 23989972]

70. Im SC, Waskell L. The Interaction of Microsomal Cytochrome P450 2B4 with its Redox Partners, Cytochrome P450 Reductase and Cytochrome $b_{5}$. Arch. Biochem. Biophys. 2011; 507:144-153. [PubMed: 21055385]

71. Durr UHN, Yamamoto K, Im SC, Waskell L, Ramamoorthy A. Solid- State NMR Reveals Structural and Dynamical Properties of a Membrane-Anchored Electron-Carrier Protein, Cytochrome b5. J. Am. Chem. Soc. 2007; 129:6670-6671. [PubMed: 17488074]

72. Ahuja S, Jahr N, Im SC, Vivekanandan S, Popovych N, Le Clair SV, Huang R, Soong R, Xu J, Yamamoto K, Nanga RP, Bridges A, Waskell L, Ramamoorthy A. A Model of the MembraneBound Cytochrome $\mathrm{b}_{5}$-Cytochrome P450 Complex from NMR and Mutagenesis Data. J. Biol. Chem. 2013; 288:22080-22095. [PubMed: 23709268]

73. Palmer AG, Skelton NJ, Chazin WJ, Wright PE, Rance M. Suppression of the Effects of CrossCorrelation between Dipolar and Anisotropic Chemical-Shift Relaxation Mechanisms in the Measurement of Spin Spin Relaxation Rates. Mol. Phys. 1992; 75:699-711. 
74. Delaglio F, Grzesiek S, Vuister GW, Zhu G, Pfeifer J, Bax A. NMRpipe - a Multidimensional Spectral Processing System Based on Unix Pipes. J. Biomol. NMR. 1995; 6:277-293. [PubMed: 8520220]

75. Kneller DG, Kuntz ID. Ucsf Sparky - an NMR Display, Annotation and Assignment Tool. J. Cell Biochem. 1993:254-254.

76. Storch EM, Daggett V. Molecular-Dynamics Simulation of Cytochrome $b_{5}$ - Implications for Protein-Protein Recognition. Biochem. 1995; 34:9682-9693. [PubMed: 7626638]

77. Fushman D, Cowburn D. Model-Independent Analysis of ${ }^{15} \mathrm{~N}$ Chemical Shift Anisotropy from NMR Relaxation Data. Ubiquitin as a Test Example. J. Am. Chem. Soc. 1998; 120:7109-7110.

78. Pintacuda G, Kaikkonen A, Otting G. Modulation of the Distance Dependence of Paramagnetic Relaxation Enhancements by CSA X DSA Cross-Correlation. J. Magn. Reson. 2004; 171:233243. [PubMed: 15546749]

79. Otting G. Protein NMR Using Paramagnetic Ions. Annu. Rev. Biophys. 2010; 39:387-405. [PubMed: 20462377]

80. Gueron M. Nuclear-Relaxation in Macromolecules by Paramagnetic Ions: A Novel Mechanism. J. Magn. Reson. 1975; 19:58-66.

81. Vega AJ, Fiat D. Nuclear-Relaxation Processes of Paramagnetic Complexes The S-Motion Case. Mol. Phys. 1976; 31:347-355.

82. Dangi B, Blankman JI, Miller CJ, Volkman BF, Guiles RD. Contribution of Backbone Dynamics to Entropy Changes Occurring on Oxidation of Cytochrome b $_{5}$. Can Redox Linked Changes in Hydrogen Bond Networks Modulate Reduction Potentials? J. Phys. Chem. B. 1998; 102:82018208.

83. Vivekanandan S, Ahuja S, Im SC, Waskell L, Ramamoorthy A. ${ }^{1} \mathrm{H},{ }^{13} \mathrm{C}$ and ${ }^{15} \mathrm{~N}$ Resonance Assignments for the Full-Length Mammalian Cytochrome $b_{5}$ in a Membrane Environment. Biomol. NMR Assign. 2013 DOI 10.1007/s12104-013-9528-9.

84. Zech SG, Olejniczak E, Hajduk P, Mack J, McDermott AE. Characterization of Protein-Ligand Interactions by High-Resolution Solid-State NMR Spectroscopy. J. Am. Chem. Soc. 2004; 126:13948-13953. [PubMed: 15506755]

85. Jovanovik T, Harris M, McDermott AE. Cytochrome P450 BM-3 in Complex with Its Substrate: Temperature-Dependent Spin State Equilibria in the Oxidized and Reduced States. Appl. Magn. Reson. 2007; 31:411-429.

86. Knight MJ, Felli IC, Pierattelli R, Emsley L, Pintacuda G. Magic Angle Spinning NMR of Paramagnetic Proteins. Acc. Chem. Res. 2013; 46:2108-2116. [PubMed: 23506094]

87. Knight MJ, Pell AJ, Bertini I, Felli IC, Gonnelli L, Pierattelli RA, Herrmann T, Emsley L, Pintacuda G. Structure and Backbone Dynamics of a Microcrystalline Metalloprotein by SolidState NMR. Proc. Natl. Acad. Sci. U S A. 2012; 109:11095-11100. [PubMed: 22723345] 
(A)

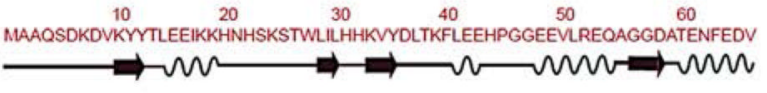
$\begin{array}{ccccccc}70 & 80 & 90 & 100 & 110 & 120 & 130 \\ \text { GHSTDARELSKTFIIGELHPDDRSKLSKPMMETLITTVDSNSSWWTNWWIPAISALIVALMYRLYMADD }\end{array}$

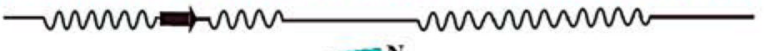

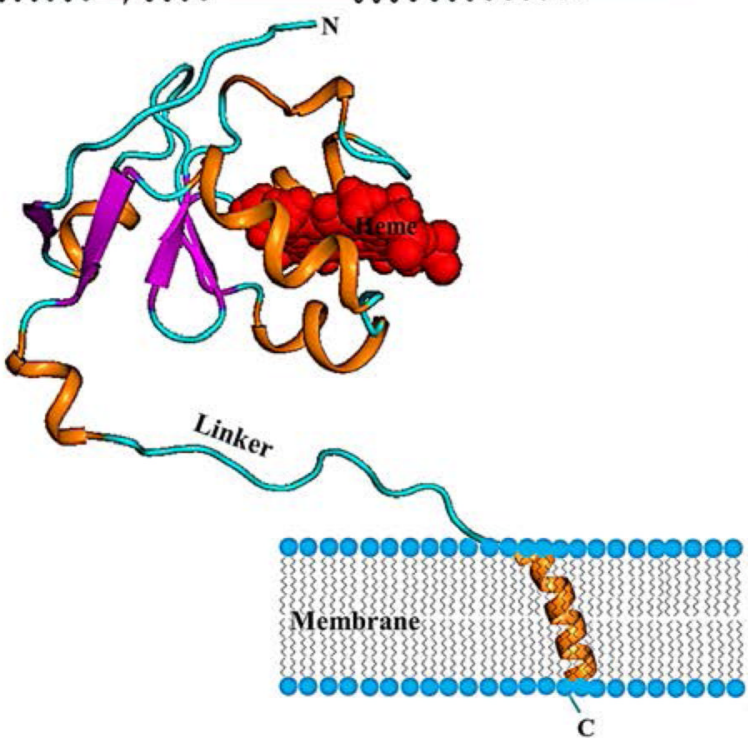

(B)

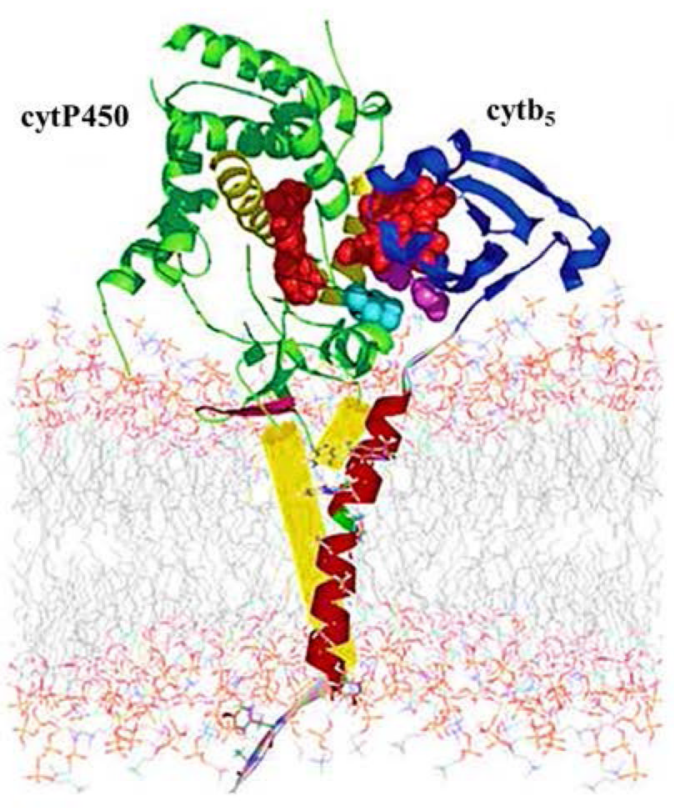

Figure 1. NMR structure of rabbit microsomal cytb $b_{5}$ and a cartoon representation of its complex with cytP450

(A) NMR structure of a full-length membrane-bound cytb ${ }_{5}$ along with its amino acid sequence. The structure was obtained from a combination of solution and solid-state NMR experiments. The solution NMR method was used to solve the structure of the soluble heme domain (residues 1-104) of full-length cytb ${ }_{5}$ incorporated in DPC micelles while the structure of the transmembrane domain (residues 106-126) of full-length cytb $\mathrm{b}_{5}$ incorporated in aligned DMPC/DHPC bicelles was determined using solid-state NMR spectroscopy. (B) A representation of the cytP450-cytb 5 complex illustrating interactions of different domains of cytb 5 with its redox partner cytP450. 

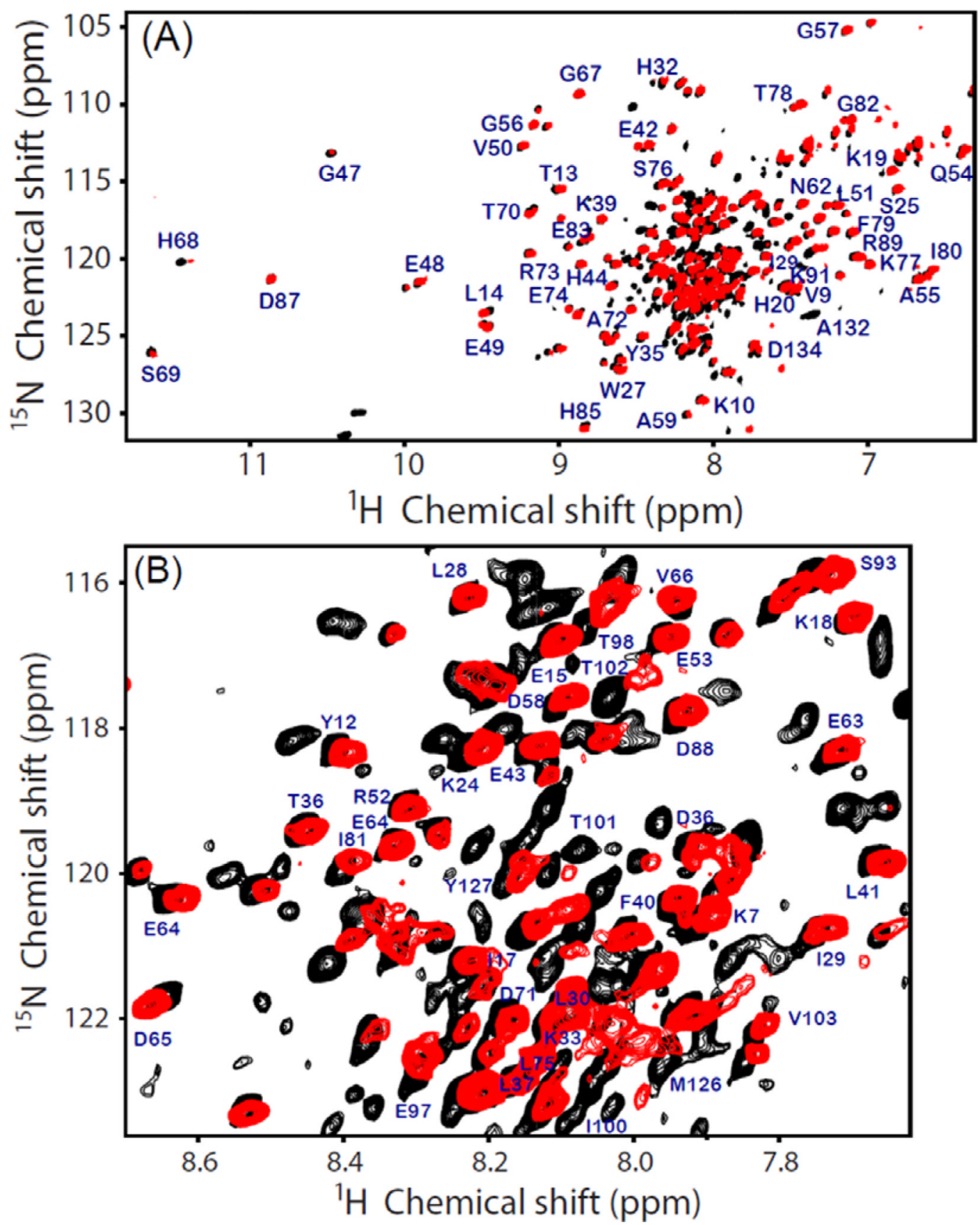

Figure 2. TROSY-HSQC spectra of membrane-bound cytb 5 in the presence and the absence of cytP450

(A) $2 \mathrm{D}^{15} \mathrm{~N}-{ }^{1} \mathrm{H}$ TROSY-HSQC spectra of a $\mathrm{U}-{ }^{15} \mathrm{~N},{ }^{13} \mathrm{C},{ }^{2} \mathrm{H}$ labeled full-length cytb incorporated in DPC micelles both in free (black) and in complexation with cytP450 (red) along with residue specific resonance assignments. (B) An expansion of the crowded region of the full 2D spectrum (A). 


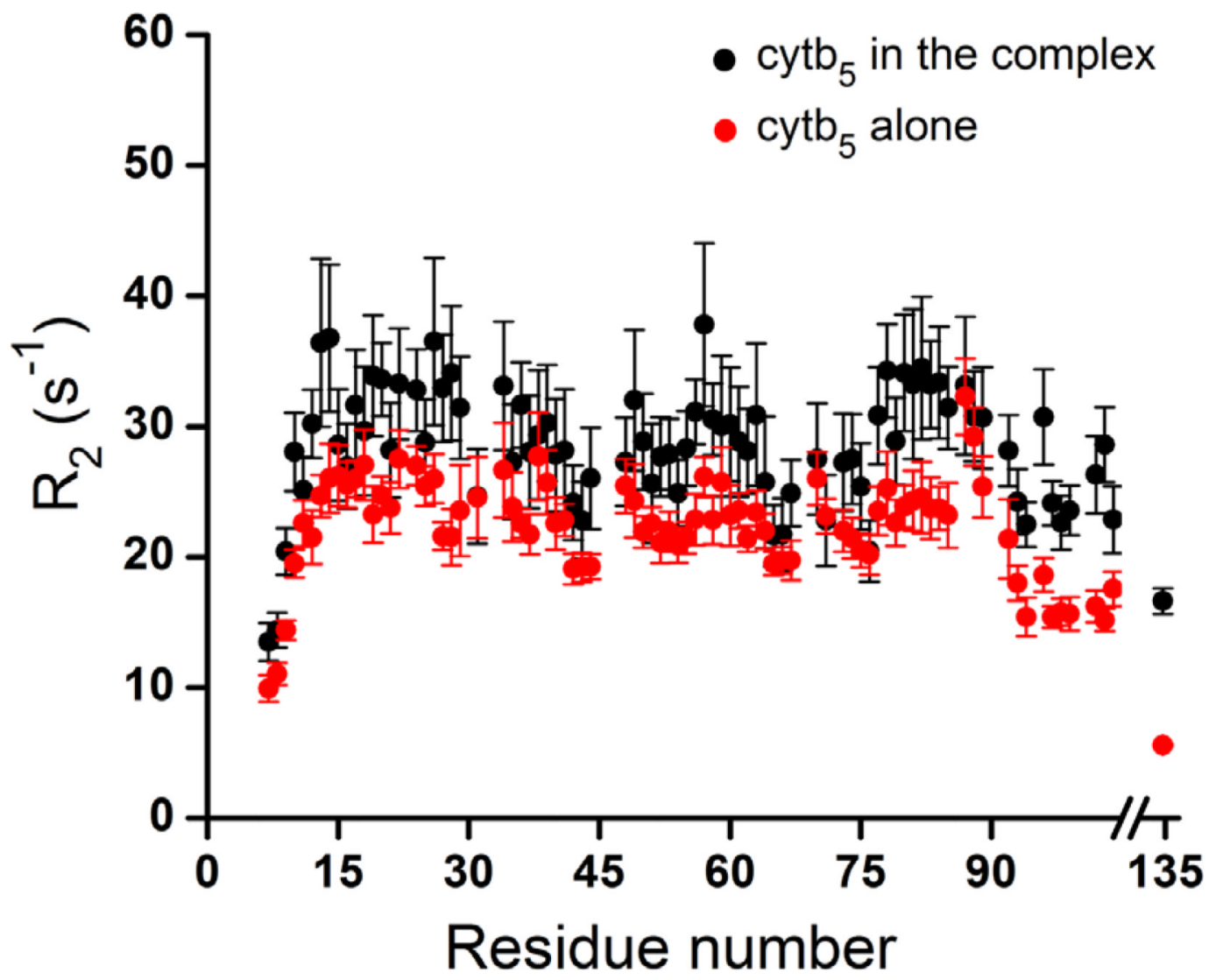

Figure 3. Backbone amide- ${ }^{15} \mathrm{~N}$ transverse relaxation rates, $R_{2}$, for cytb $b_{5}$ residues in DPC micelles

Amide- $-{ }^{15} \mathrm{~N}$ transverse relaxation rates for cytb 5 alone (red) and in complex with cytP450 (black) are plotted against the residue number. 


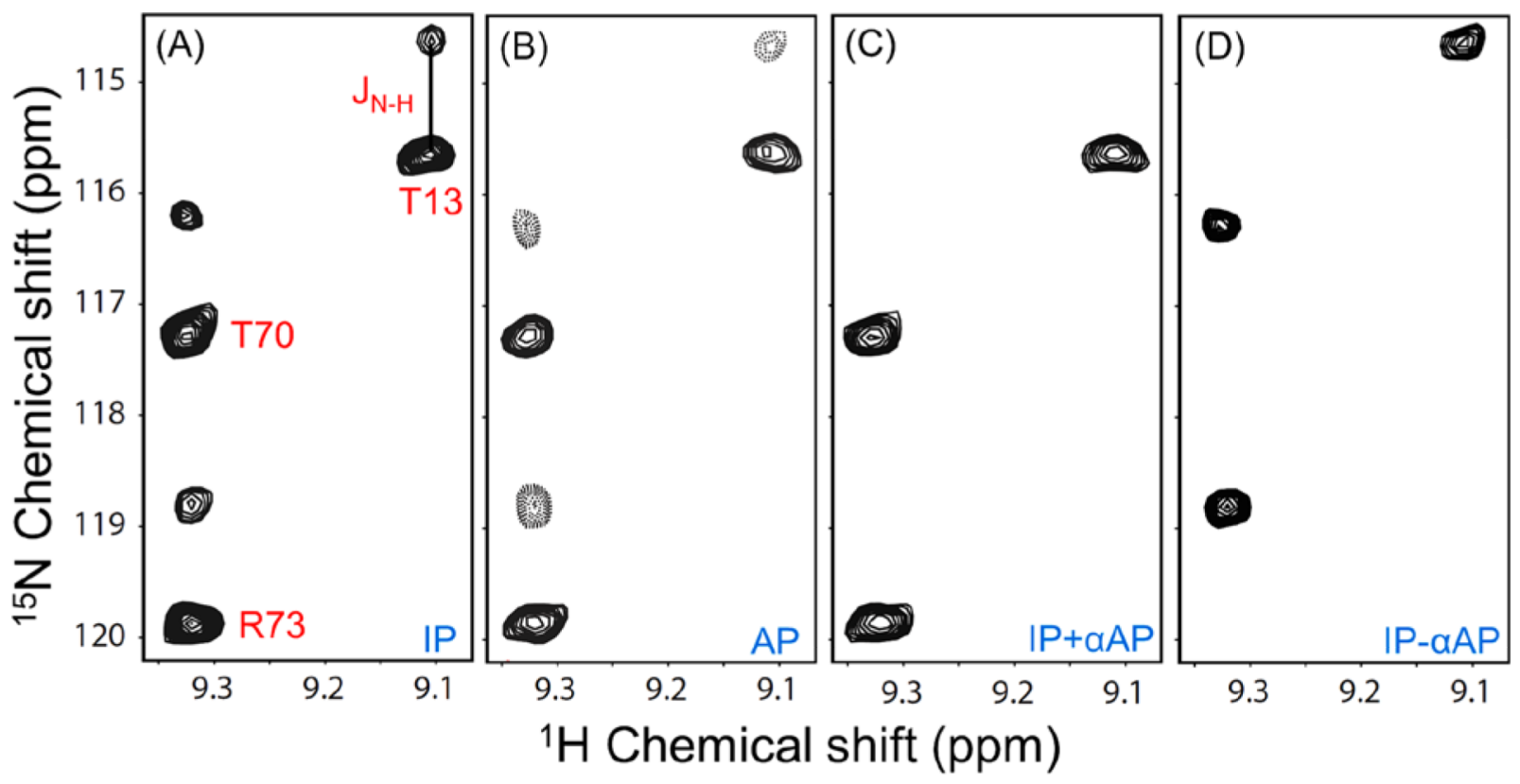

Figure 4. Representative regions of proton-coupled $2 \mathrm{D}{ }^{1} \mathrm{H} /{ }^{15} \mathrm{~N}$ IPAP spectra of a uniformly- ${ }^{15} \mathrm{~N},{ }^{13} \mathrm{C}$ and ${ }^{2} \mathrm{H}$-labeled cytb 5 in the cytb $5-\mathrm{P450}$ complex incorporated in DPC micelles

(A) in-phase (IP) ${ }^{15} \mathrm{~N}-{ }^{1} \mathrm{H}$ doublets, (B) anti-phase (AP) ${ }^{15} \mathrm{~N}-{ }^{1} \mathrm{H}$ doublets, (C) simplified sum (IP- $\alpha$ AP) and (D) difference (IP+ $\alpha$ AP) spectra. The spectra were recorded on a $900 \mathrm{MHz}$ NMR spectrometer using a relaxation delay of $10.64 \mathrm{~ms}$. The transverse magnetization of ${ }^{15} \mathrm{~N}$ nuclei was aled to evolve under ${ }^{15} \mathrm{~N}$ chemical shift and ${ }^{15} \mathrm{~N}-{ }^{1} \mathrm{H}$ scalar couplings during the $t_{1}$ period of the pulse sequence. 

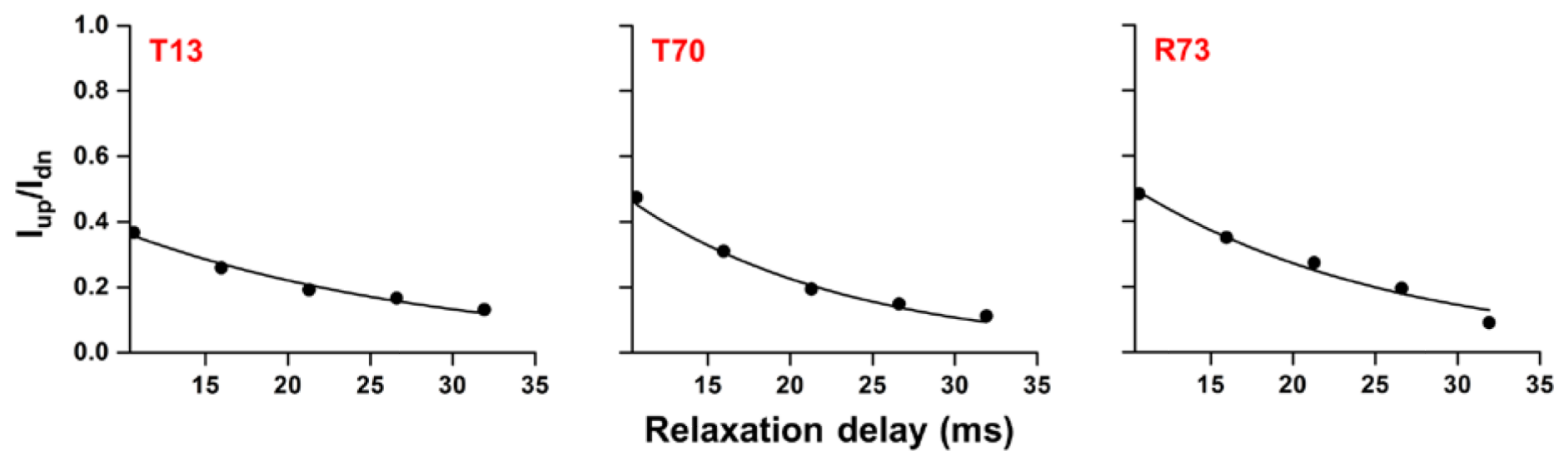

Figure 5. Transverse cross-correlated rates $\left(\eta_{x y}\right)$ measurement The mono-exponential decay curves for the measurement of transverse cross-correlated rates $\left(\eta_{x y}\right)$ from the ratio of the up-field and the down-field peak intensities $\left(I_{\mathrm{up}} / I_{\mathrm{dn}}\right)$ for residues T13, T70 and R73 plotted against the relaxation delay time $(\Delta)$. The corresponding values of $\eta_{x y}$ for these residues are $12.78 \pm 1.12 \mathrm{~s}^{-1}, 18.35 \pm 1.53 \mathrm{~s}^{-1}$ and $15.79 \pm 2.09 \mathrm{~s}^{-1}$, respectively. 


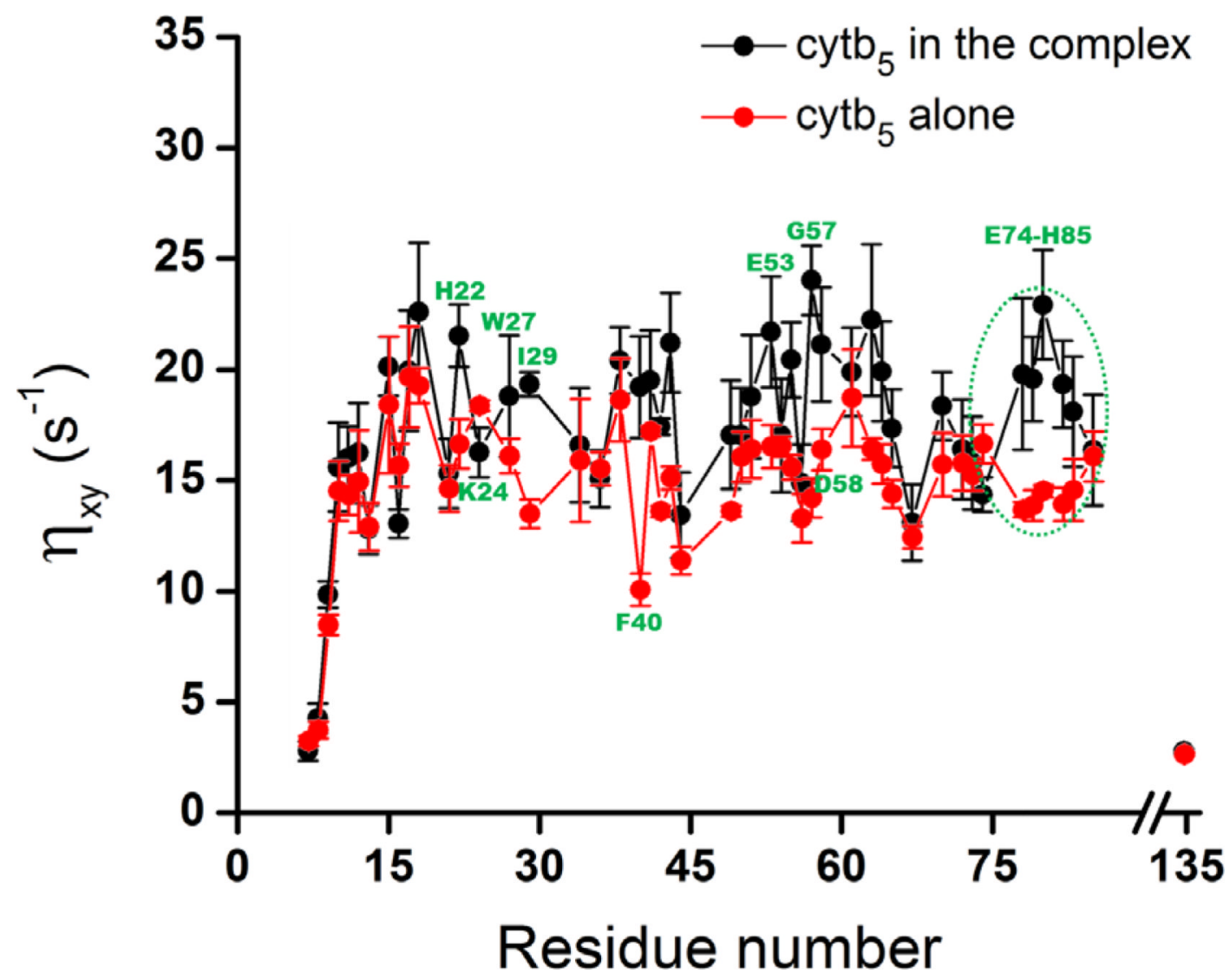

Figure 6. Backbone amide- ${ }^{15} \mathrm{~N}$ transverse cross-correlated rates, $\eta_{x y}$, for cytb5 residues Backbone amide- ${ }^{15} \mathrm{~N}$ transverse cross-correlated rates obtained from mono-exponential

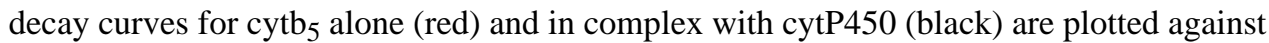
residue number. The transmembrane region of the protein, which could not be observed in solution-NMR due to its s dynamics, is represented by a break on the horizontal axis. 

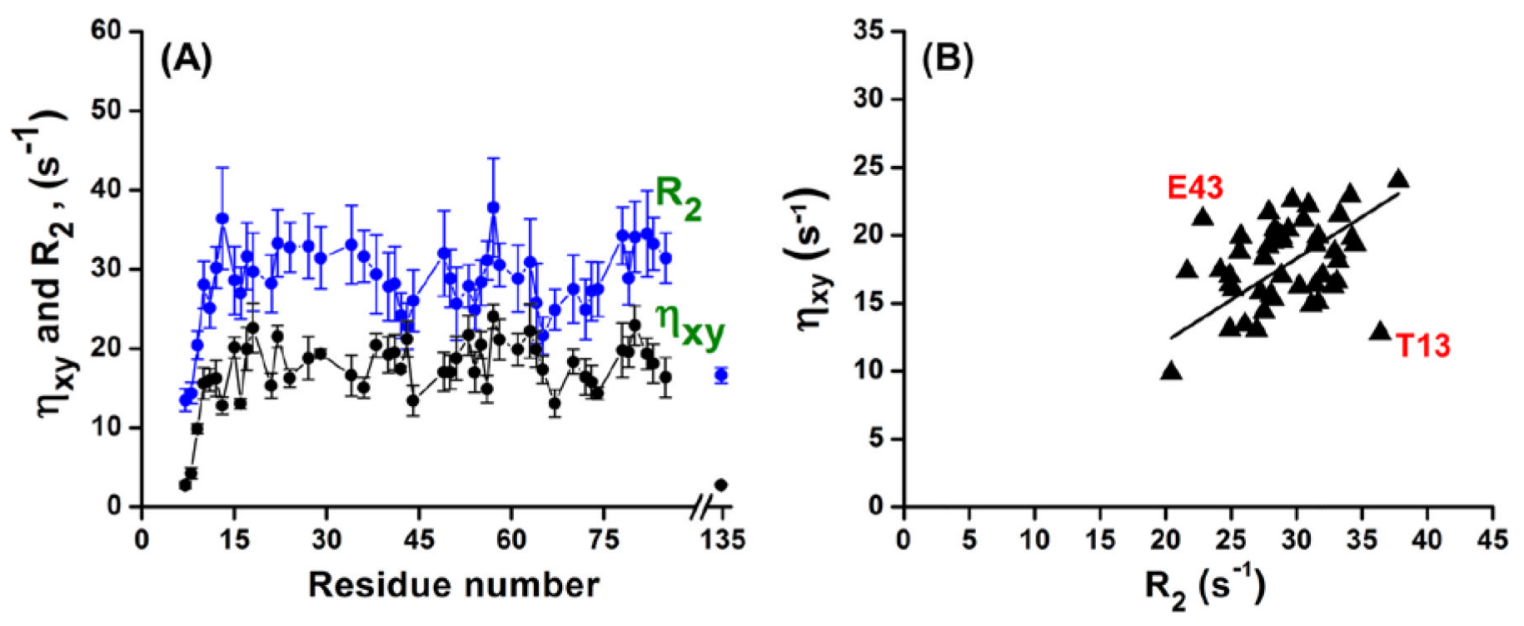

Figure 7. A comparison of the backbone amide- ${ }^{15} \mathrm{~N}$ transverse cross-correlation rate with the transverse relaxation rate

(A) A comparison between the derived backbone amide- ${ }^{15} \mathrm{~N}$ CSA-dipolar cross-correlated rate $\left(\eta_{x y}\right)$ and the transverse relaxation rate $\left(R_{2}\right)$. (B) A linear correlation with a slope $=0.61 \pm 0.02$. 


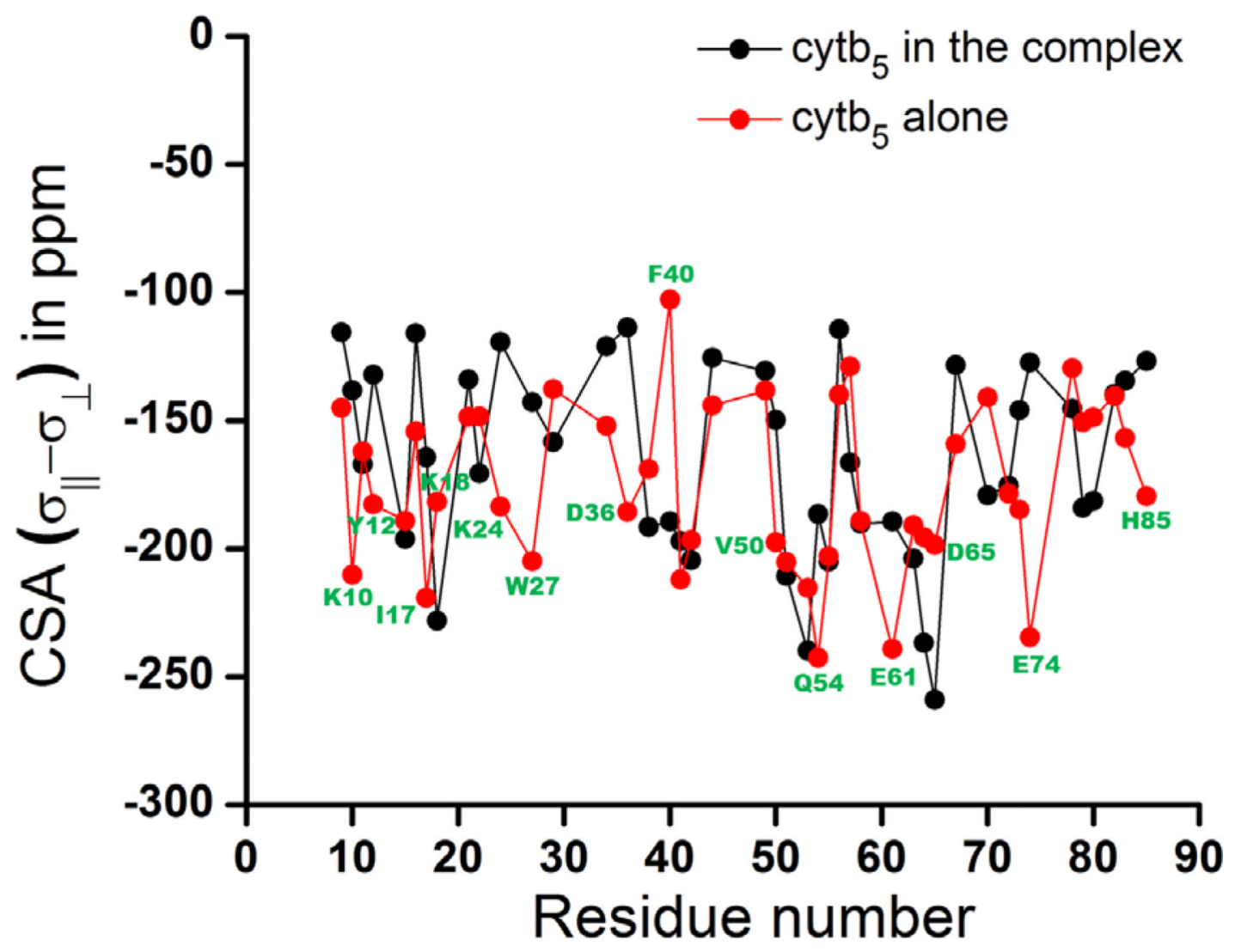

Figure 8. Experimentally determined amide- ${ }^{15} \mathrm{~N}$ CSA values for cytb 5

Comparison of the variation of amide- ${ }^{15} \mathrm{~N}$ CSA for cytb ${ }_{5}$ determined from DPC micelle samples containing cytb 5 or cytb ${ }_{5}$-cytP450 complex. The ${ }^{15} \mathrm{~N} \mathrm{CSA}\left(\sigma_{\|}-\sigma_{\perp}\right)$ tensors of cytb $_{5}$ were determined by taking an effective internuclear distance between amide nitrogen and proton atoms $\left(r_{\mathrm{N}-\mathrm{H}}\right)$ as $1.023 \AA$ and a constant value for the angle $\left(\beta=18^{\circ}\right)$ between the amide-N-H bond and the least shielded component of the CSA tensor. 